\title{
Der Umgang mit religiösen Minderheiten in der österreichischen Armee
}

\author{
Wolfram Reiss
}

\begin{abstract}
Already at the time of the Habsburg Monarchy the Protestant, Jewish, Orthodox and Muslim Soldiers of the Austro-Hungarian army enjoyed special rights and privileges of religious assistance. A complex system of multireligious military chaplaincy existed in the Habsburg Empire. Also the Armed Forces of the Second Austrian Republic have regulations in place for religious assistance to minority faiths, albeit under radically different circumstances. This article analyses the development of military chaplaincy in Austria from the Habsburg period to the present. It shows that in some cases practices of the past were more progressive than today's regulations. The article asks to what extent presentday regulations of military chaplaincy in Austria meet the requirements of the right to free religious practice of professional soldiers and recruits.
\end{abstract}

Wolfram Reiss, professor for studies of religions, University of Vienna. $1998 \mathrm{PhD}$ on Revival of the Coptic Orthodox Church; 2005 Habilitation thesis on The Portrayal of Christianity in Egyptian textbooks. Lutheran prison chaplain in a high security jail in Germany 2005-2007. Main research fields: Islam and Oriental Christianity; studies in contemporary religious, political and social developments in the Middle East, studies in religious diversity in state institutions in Europe. Editor of the series "Anwendungsorientierte Religionswissenschaft". Recent publications (2015/2016): Religion im Wandel. Transformation religiöser Gemeinschaften in Europa durch Migration. Interdisziplinäre Perspektiven, co-edited with Regina Polak (Vienna 2015); "Selbstbetrachtung hinter Gittern. Naikan im Strafvollzug in Deutschland und Österreich" (forthcoming) "Rise and Fall of the Muslim Brotherhood in Egypt 2011-2013" (forthcoming).

\section{Einleitung}

Bereits in der k. u. k. Donaumonarchie gab es für evangelische, jüdische, orthodoxe und muslimische Soldaten besondere Regelungen, und eine umfassende Betreuung wurde in Form einer multireligiösen Militärseelsorge aufgebaut. In jüngerer Gegenwart wurde auch im österreichischen Bundesheer der zweiten Republik wieder eine Militärseelsorge für religiöse Minderheiten eingeführt, allerdings unter veränderten Rahmenbedingungen und mit neuen Regelungen. Der Beitrag beschreibt diese Entwicklungen, zeigt auf, dass ältere Vorschriften teilweise weiter gingen als die heutigen, und fragt danach inwieweit die derzeit vorhandenen Regelungen dem Recht auf Religionsausübung gerecht werden. 


\section{Der Umgang mit religiösen Minderheiten in der Armee während der k. u. k Monarchie}

Die im 18. Jh. erlassenen Toleranzpatente Josephs II. leiteten das Ende der Diskriminierung der religiösen Minderheiten im Habsburgerreich ein. Das Patent vom 13.10.1781 ermöglichte zunächst den im Westfälischen Frieden anerkannten protestantischen Kirchen (Augsburgisches Bekenntnis und Helvetisches Bekenntnis) und den orthodoxen Kirchen offiziell die Religionsausübung, wenn auch noch mit gewissen Einschränkungen. Am 2.1.1782 wurde auch für Juden ein Toleranzedikt erlassen, das die jüdische Emanzipation einleitete. Die Okkupation von Bosnien-Herzegowina 1878 hatte die Eingliederung von zahlreichen muslimischen und serbisch-orthodoxen Untertanen zur Folge. Die Gewährung bürgerlicher Rechte für die religiösen Minderheiten hatte die Folge, dass Regelungen getroffen werden mussten zur Wahrung ihrer staatsbürgerlichen Pflichten, die den Militärdienst inkludierten. ${ }^{1}$

\subsection{Evangelische in der k. u. k. Armee}

Mit dem Toleranzpatent von 1781 wurden den Protestanten zunächst nur eingeschränkt Möglichkeiten gegeben, ihrer Religion nachzugehen. Soldaten durften Bethäuser der sich konstituierenden Gemeinden besuchen - sofern solche in der Nähe waren. Evangelischen Geistlichen wurde nur in Ausnahmefällen der Zutritt zu Kasernen gewährt, z. B. zum Besuch von Kranken und Sterbenden. ${ }^{2}$ Erst 1834 wurde die evangelische Militärseelsorge für das augsburgische und das helvetische Bekenntnis in der k.u.k. Armee institutionalisiert, sie unterstand allerdings der römisch-katholischen Militärseelsorge. ${ }^{3}$ Ab 1860 wurden jeweils zwei evangelische Garnisonsfeldprediger - für reformierte und lutherische Soldaten flächendeckend im Habsburgerreich - eingeführt und finanziell den katholischen Kollegen gleichgestellt. In den darauffolgenden Jahrzehnten konnte sich die evangelische Militärseelsorge fest etablieren. So waren zwischen 1860 und 1914 mindestens 30 evangelische Militärgeistliche angestellt und 1861 wurde die Wiener Schwarzspanierkirche als evangelische Garnisonskirche zur Verfügung gestellt. ${ }^{4}$ Während des Ersten Weltkrieges vervielfachte sich die Zahl der evangelischen Feldgeistlichen und wuchs auf insgesamt 3.077 Personen an. Zum Teil hatte das mit Bestimmungen des Heeres zu tun, dass im Kriegsfall die Zahl der Geistlichen für jede Truppendivision eine Militärseelsorge aus mindestens zwei Militärgeistlichen aus dem Reservestand einzurichten hatte. Zum Teil hatte das

1 Berger 2010, S. 27.

2 Reichl-Ham 2005, S. 12.

3 Gröger / Ham / Sammer 2001, S. 19 ff.

4 Reichl-Ham 2005, S. 26; ausführlich: Trauner 2011. 
auch mit der (anfänglichen) Kriegsbegeisterung zu tun, die katholische wie auch evangelische Theologen gleichermaßen beflügelt hatte, sich freiwillig zu melden. ${ }^{5}$

\subsection{Juden in der k. u. k. Armee}

Auch für Juden wurde 1788 die Militärpflicht in allen habsburgischen Ländern eingeführt. ${ }^{6}$ Viele Juden sahen das Militär als Möglichkeit staatsbürgerliche Anerkennung zu erlangen, da jüdische Soldaten im Militär weniger Benachteiligungen ausgesetzt waren. ${ }^{7}$ In der Zeit von 1788 bis zum Ende der Monarchie dienten in der Armee Österreich-Ungarns 1.000 jüdische Berufsoffiziere, im Reserveoffizierskorps war fast jeder Fünfte ein bekennender Jude. Im Deutschen Kaiserreich hingegen wurde kein einziger Jude zum Reserveoffizier befördert. Juden wurden für ihre Verdienste geadelt und konnten auch in höchste Offiziersränge aufsteigen. ${ }^{8}$ Auf die Sabbatruhe, die Befreiung vom Dienst sowie die koschere Verpflegung wurde Rücksicht genommen. ${ }^{9}$ Mit der Einführung der allgemeinen Wehrpflicht stieg auch die Zahl der jüdischen Soldaten in der Armee weiter an. 1872 waren es mehr als 12.000, 1902 fast 60.000. Von mehr als 26.000 Offizieren waren im Jahre 1894 knapp 2.200 Juden. In der österreichischen Landwehr waren etwa ein Drittel der Offiziere Juden, in einzelnen Regimentern sogar mehr als die Hälfte. ${ }^{10}$ Eine seelsorgliche Betreuung jüdischer Soldaten war anfangs nicht vorgesehen. 1859 kam erstmals ein Feldrabbiner zum Einsatz, seit 1874 begann man Feldrabbiner der Reserve einzusetzen. Die Betreuung jüdischer Soldaten in Friedenszeiten erfolgte durch örtliche zivile Rabbiner. Dies änderte sich im Ersten Weltkrieg. Es wurden insgesamt 76 Feldrabbiner einberufen, die im Range eines Hauptmanns waren und sich um die religiösen Bedürfnisse der Juden kümmerten. ${ }^{11}$ Insgesamt dienten in der k. u. k. Armee während des Ersten Weltkriegs 300.000 jüdische Soldaten und 25.000 jüdische Offiziere. ${ }^{12}$ In der Rossauerkaserne wurde eine Synagoge eingerichtet. Ansonsten wurden Gebete in lokalen Synagogen oder in Feldgottesdiensten durchgeführt. ${ }^{13}$ Nach dem Ersten Weltkrieg sollte diese Erfolgsgeschichte der jüdischen Integration im Militär jedoch zu Ende sein.

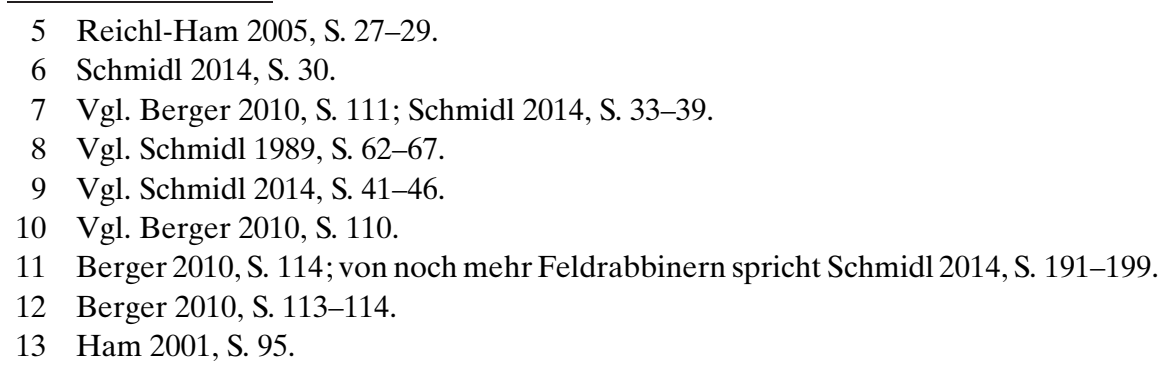




\subsection{Orthodoxe in der k. u. k. Armee}

Während der Zeit der k. u. k. Monarchie wurde auch eine „griechisch-orientalische“ (d. h. orthodoxe) Militärseelsorge eingeführt. Bereits 1758 wurde festgelegt, dass in jeder Division der Grenztruppen, in denen ein hoher Prozentsatz von orthodoxen Soldaten vorhanden war, ein orthodoxer Kaplan in Kriegszeiten angestellt werden sollte, doch erst ab 1858 kann man von einer funktionierenden orthodoxen Militärseelsorge sprechen, denn nunmehr regelte ein Erlass, dass in allen Regimentern mit ca. 1000 orthodoxen Soldaten Regimentskapläne angestellt werden sollten. Das erhöhte die Anzahl der Kapläne auf sieben. ${ }^{14} 1869$ wurde das Amt eines Militärerzpriesters eingeführt, dem neun griechisch-orientalische Militärkapläne unterstanden. Die Kapläne waren den katholischen Geistlichen gleichgestellt. ${ }^{15}$ Mit der Okkupation Bosnien-Herzegowinas 1878 und der Einführung der allgemeinen Wehrpflicht im Jahr 1882 vermehrte sich die Zahl der orthodoxen Soldaten erheblich. Zeitweise gehörte fast die Hälfte aller Rekruten der serbisch-orthodoxen Kirche an. Im Offizierskorps waren die Orthodoxen allerdings unterrepräsentiert. ${ }^{16}$ Während des Ersten Weltkriegs muss die Zahl der orthodoxen Geistlichen wie bei den anderen Religionsgruppen erheblich gestiegen sein und mehrere hundert Priester umfasst haben.

\subsection{Muslime in der k. u. k. Armee}

Die Soldaten der bosnisch-herzegowinischen Regimenter werden heute meist als muslimische Soldaten in Erinnerung bewahrt. Dies ist jedoch nicht richtig, denn nur ein Drittel der bosnisch-herzegowinischen Soldaten waren Muslime; viele waren auch Juden oder Orthodoxe. ${ }^{17}$ Unter den Berufsoffizieren gab es vor 1914 kaum Muslime. ${ }^{18} 1913$ gab es bei den bosnisch-herzegowinischen Truppen nur 6 muslimische, aber 549 römisch-katholische, 61 orthodoxe, 40 jüdische und 29 protestantische Stabs- und Oberoffiziere, ${ }^{19}$ kein einziger wurde General. ${ }^{20}$ Die Truppen waren mit Soldaten aller Religionen besetzt, es gab keine nach Religionen oder Ethnien getrennten Einheiten. ${ }^{21}$ Ab 1891 begann eine Verlegung der bosnisch-herzegowinischen Einheiten nach Wien, Budapest und später auch nach

14 Neumayer / Schmidl 2008, S. 118.

15 Ham 2001, S. 65.

16 Neumayer/Schmidl 2008, S. 117.

17 Neumayer/Schmidl 2008, S. 72.

18 Neumayer/Schmidl 2008, S. 73.

19 Neumayer / Schmidl 2008, S. 117.

20 Neumayer/Schmidl 2008, S. 104.

21 Neumayer/Schmidl 2008, S. 72. 
Graz.22 1900 lebten in Wien 2.240 Bosnier und Herzegowiner, davon 2.059 Soldaten. Vor dem Ersten Weltkrieg umfassten die Aufgaben der bosnisch-herzegowinischen Soldaten vornehmlich die Präsenz bei Frühjahrsparaden und Wachdienste in der Hofburg, sowie Assistenzeinsätze, ${ }^{23}$ die sich oft gegen die österreichische Bevölkerung richteten. So wurden sie z. B. bei den „Teuerungskrawallen“ in Wien 1911 eingesetzt. Dabei handelte es sich um Demonstrationen von Österreichern gegen die gestiegenen Lebensmittel- und Wohnungskosten. ${ }^{24}$ Ebenso kam es bei anderen Gelegenheiten zu Auseinandersetzungen. ${ }^{25}$ Sowohl mit der Bevölkerung als auch innerhalb der bosnischen Regimenter scheint es also Spannungen gegeben zu haben. Von Seiten des Heeres gab es allerdings intensive Bemühungen, den religiösen Bedürfnissen der muslimischen Rekruten entgegenzukommen. So wurden bereits vor der Einführung der allgemeinen Militärpflicht Erkundigungen eingeholt, wie man mit muslimischen Soldaten umgehen sollte und es wurden Vorschriften erlassen, mit denen man versuchte, auf die Bedürfnisse der muslimischen Soldaten einzugehen: Islamische Lehrer von Medresen, Imame und Scheiche wurden von der Wehrpflicht ausgenommen; Freitage sollten als Ruhetage für die muslimischen Soldaten gelten; anlässlich des Ramadan- und des Opferfestes waren muslimische Soldaten mehrere Tage frei zu stellen. ${ }^{26}$ Essen durfte gesondert zubereitet werden, sollten es nicht von der Versorgungsstelle geliefert werden können. Es wurde eigenes Kochgeschirr bereitgestellt. Auf die Speisevorschriften sollte geachtet werden. ${ }^{27}$ Bei ärztlichen Untersuchungen sollten Muslime aufgrund ihres größeren Schamgefühls einzeln und in gesonderten Räumen untersucht werden. Muslime, die sich nicht im Dienst befanden, durften das Freitagsgebet zwischen 11 und 13 Uhr verrichten. Gebete für die Bairam-Feste sollten in einer Moschee stattfinden. Sollte eine solche nicht zur Verfügung stehen, war ein Raum oder ein Platz mit Möglichkeiten für die rituelle Waschung bereit zu stellen (z.B. in der Alserkaserne sowie in der Erzherzog-Albrecht-Kaserne) ${ }^{28}$ Einige muslimische Soldaten erhielten eine zusätzliche Ausbildung in Krankenpflege und wie sie Beistand im Todesfall leisten konnten bzw. wie sie die rituelle Totenwaschung durchführen mussten. ${ }^{29}$ Hadži Mehmed Effendi Kokić wurde 1882 zum ersten Militärimam im Rang eines

\footnotetext{
22 Neumayer/Schmidl 2008, S. 52.

23 Vgl. Neumayer / Schmidl 2008, S. 55 ff.

24 Vgl. Neumayer / Schmidl 2008, S. 57 ff.

25 Vgl. Neumayer/Schmidl 2008, S. 59-62.
}

26 Diese Regelung traf allerdings nicht für Soldaten $\mathrm{zu}$, die an denselben Tagen im Waffendienste stehen.

27 So in einem „Verordnungsblatt für das k. u. k. Heer: Circularverordnung vom 4. November 1881, Präs. Nr. 6.015, 248“ zitiert nach Neumayer / Schmidl 2008, S. 99 und 183 (Fußnote 97).

28 Neumayer / Schmidl 2008, S. 59, 99.

29 Vgl. Neumayer/Schmidl 2008, S. 101. 
Hauptmannes ernannt. 1914 waren bereits 14 Militärimame in den bosnischherzegowinischen Truppen tätig. Konnte der Imam nicht anwesend sein, gab es auch sogenannte „muslimische Subsidarseelsorger“ ${ }^{30}$ Im Jahr 1914 wurde Abdullah Effendi Kurbegović zum Militärmufti ernannt. Während des Ersten Weltkriegs wuchs die Zahl der islamischen Militärimame gewaltig an. 1918 gab es den Militärmufti, zwei Hauptimame, fünf Imame in Reserve und 93 Militärimame in Reserve auf Kriegsdauer. ${ }^{31}$

Nachdem das Osmanische Reich offiziell am 11. November 1914 den Dschihad gegen die alliierten Mächte proklamiert hatte, wurden die bosnischen Soldaten zum Dschihad aufgefordert, da Österreich-Ungarn als Verbündeter des Osmanischen Reiches an der Seite des Kalifen kämpfe. ${ }^{32}$ Nicht mehr realisiert werden konnte ein Großprojekt zum Bau einer repräsentativen Moschee in Wien zum Dank für den Einsatz der bosnisch-herzegowinischen Truppenangehörigen. Kaiser Franz Joseph selbst soll 25.000 Goldkronen dafür gespendet haben. Die Gemeinde Wien war bereit, ein Grundstück im Türkenschanzpark oder im MariaJosepha-Park, dem heutigen Schweizergarten vor dem Arsenal, dafür bereit zu stellen. Bis Mai 1918 waren 260.000 Kronen für den Erwerb des Grundstücks zusammengetragen. Auch Kaiser Karl spendete noch im Juli 191830.000 Kronen für den Baufonds. Diese Moschee sollte nach einer Verlautbarung des Kriegsministeriums vom 12. Juli 1918 „,neuerdings [...] beweisen, wie sehr die Bevölkerung der Monarchie auch ihren jüngsten Mitbürgern zugetan ist“ und „[...] für die Mohammedaner Österreich-Ungarns ein bleibendes Denkmal der großen Zeit sein, in welcher sie Schulter an Schulter mit den übrigen Untertanen Seiner Majestät Gottes mächtige Hilfe für ihre Waffen gefunden haben.“33

\subsection{Das Ende der multireligiösen Bemühungen mit Ende des Ersten Weltkrieges}

Nach dem Ende des Ersten Weltkrieges wurde Bosnien-Herzegowina Teil des Königreichs der Serben, Kroaten und Slowenen (Jugoslawien), so dass keine muslimischen Soldaten mehr im 1920 gegründeten österreichischen Bundesheer der Ersten Republik (1920-1934) dienten. Auch die Zahl der jüdischen und orthodoxen Soldaten nahm drastisch ab, weil das Heer insgesamt gemäß des Friedensvertrags von St. Germain auf 30.000 Berufssoldaten verkleinert wurde. ${ }^{34}$ Auf Sabbatruhe und Speisegesetze wurde kaum noch Rücksicht genommen. Proteste hiergegen wurden abgewiesen. ${ }^{35}$ Der zunehmende Antisemitismus und die Nazi-

30 Neumayer / Schmidl 2008, S. 110.

31 Neumayer/Schmidl 2008, S. 113.

32 Neumayer / Schmidl 2008, S. 138-139.

33 Zitat nach Neumayer / Schmidl 2008, S. 59.

34 Vgl. Schmidl 2014, S. 143.

35 Vgl. Reichl-Ham 2005, S. 34. 
Herrschaft führten mehr und mehr zum Ausschluss von jüdischen Soldaten und schließlich zur fast vollständigen Auslöschung bzw. Vertreibung des österreichischen Judentums im Holocaust, so dass sich die Frage nach dem Umgang mit nicht-christlichen Minderheiten in der Armee kaum noch stellte. Auch die evangelische Militärseelsorge wurde nach dem Ersten Weltkrieg zunächst beendet. Es gab sogar Befürchtungen, dass man grundsätzlich keine Angehörigen der evangelischen Konfession mehr in die Armee aufnehmen wolle. ${ }^{36}$ Als 1936 wieder die allgemeine Wehrpflicht eingeführt wurde, drängte die Evangelische Kirche auf eine Wiedereinführung evangelischer Militärseelsorge, diese hatte jedoch nur kurze Zeit Bestand, da das österreichische Bundesheer bereits am 14.3.1938 in die Deutsche Wehrmacht eingegliedert wurde. ${ }^{37}$ Eine konstante seelsorgerliche Betreuung konnte insoweit nur von der Katholischen Kirche durchgeführt werden, da dieser in Folge des Reichskonkordates von 1933 eine katholische Militärseelsorge garantiert war. Der katholische Feldbischof war in militärkirchlichen Angelegenheiten ausführendes Organ des Reichskriegsministeriums, ab 1939 des Oberkommandos der Wehrmacht und schließlich dann Adolf Hitlers selbst. ${ }^{38}$ Auf evangelischer Seite gab es in der Wehrmacht von 1934-1945 einen Feldprobst (später Feldbischof). Wenn überhaupt, gab es also neben der katholischen nur eine Berücksichtigung der religiösen Bedürfnisse der evangelischen Soldaten.

\section{Der Umgang mit religiösen Minderheiten im österreichischen Bundesheer}

\subsection{Rechtliche Sonderregelungen für religiöse Minderheiten}

Diese Situation stellte sich auch ein als 1955 das österreichische Bundesheer neu gegründet wurde. Eine katholische Militärseelsorge wurde sofort wieder eingeführt, die evangelische zwei Jahre später. Die Einführung der evangelischen Militärseelsorge wurde im \$17, Abs. 1 des Protestantengesetzes von 1961 bestätigt: „Der Bund hat der Evangelischen Kirche die Ausübung der Seelsorge an den Evangelischen Angehörigen des Bundesheeres (Evangelische Militärseelsorge) zu gewährleisten. Er hat den für die Evangelische Militärseelsorge erforderlichen Personal- und Sachaufwand in ausreichendem Maße bereitzustellen." In der konkreten Umsetzung bedeutete dies, dass in jeder der sieben evangelischen Superintendenzen ein eigener Militärpfarrer unter der Leitung eines evangelischen Militärsuperintendenten angestellt werden sollte. Die evangelische Militärseelsorge untersteht gemäß dem Protestantengesetz ( $\$ 17$ Abs. 2) in geistlichen Belangen der Evangelischen Kirche A.B. und H.B., in Verwaltungs- und Ver-

36 Vgl. Reichl-Ham 2005, S. 33.

37 Reichl-Ham 2005, S. 37.

38 Reichl-Ham 2005, S. 38. 
sorgungsangelegenheiten den jeweils zuständigen Kommandostellen. Der Staat finanziert das hauptamtliche Personal und seine Aktivitäten, stellt Kanzleien, Kirchen- und Lehrräume zur Verfügung und hält Sachmittel bereit für die Durchführung von Gottesdiensten, Unterricht und seelsorgerlichen Aktivitäten. ${ }^{39}$ In der Folge konnten evangelische Gottesdienste und Aktivitäten durchgeführt, Soldaten seelsorgerlich betreut und anlässlich des Karfreitags Dienstfreistellungen für evangelische Soldaten erwirkt werden. Neben der katholischen Militärseelsorge wurde also schon sehr früh Sorge getragen, dass auch evangelische Soldaten ihrer Religion nachgehen konnten. Vertreter anderer Religionen hatten keine Betreuung, was allerdings auch damit zusammenhing, dass es kaum Rekruten anderer religiöser Gruppen in der Armee gab.

Dies änderte sich erst im Zusammenhang mit der Anwerbung von Gastarbeitern nach dem Zweiten Weltkrieg ab den 60er Jahren. Unter den Migranten der ersten Generation waren 27,2 \% Personen aus dem ehemaligen Jugoslawien und 13,5 \% aus der Türkei, in der zweiten Generation 35,2 \% aus dem ehemaligen Jugoslawien und 24,8 \% aus der Türkei. Unter diesen Migranten wie auch unter den Migranten aus arabischen Ländern und später auch aus dem persischen Sprachraum befanden sich viele Muslime. Ihre Zahl erhöhte sich durch Familienzusammenführung, eine höhere Geburtenrate und weitere Migrationswellen so stark wie die keiner anderen Religionsgruppe ab den 1980er Jahren. ${ }^{40} 32 \%$ der ersten Generation wurden eingebürgert, während 67 \% der zweiten Generation die österreichische Staatsbürgerschaft erhielten. ${ }^{41}$ Neben den Muslimen wuchs jedoch auch die Zahl der orthodoxen Christen und auch die Zahl kleinerer Religionsgruppen erhöhte sich kontinuierlich seit den 60er Jahren. ${ }^{42}$ Die Volkszählung aus dem Jahr 2001, bei der zum letzten Mal die Religionszugehörigkeit festgehalten wurde, stellte neben 5,9 Mio. Katholiken (73,6 \%), 963.000 Religions- bzw. Bekenntnislosen (12 \% ) und 376.000 Protestanten (4,7 \% ), die Zahl von 339.000 Muslimen (4,2 \% ), 179.000 Orthodoxen (2,2 \% ), 23.000 Zeugen Jehovas, 10.000 Buddhisten, 8.000 Juden, und unter den kleineren Religionsgruppen 2.794 Sikhs fest. Etwa die Hälfte der letzteren besaß die österreichische Staatsbürgerschaft. ${ }^{43}$ Die Zahl der Muslime wuchs nach offiziellen Schätzungen bis 2009 auf knapp 516.000 Personen an (6,2 \%), von denen fast die Hälfte (49 \%) die österreichische Staatsbürgerschaft hatten. ${ }^{44}$ Die Zahl der orthodoxen Gläubigen wurde 2012 auf ca. 500.000 geschätzt, von denen mehr als die Hälfte serbischer

39 Reichl-Ham 2005, S. 41.

40 Statistik Austria 2014, S. 26-27. Vgl. Marik-Lebeck 2010, S. 7.

41 Statistik Austria 2014, S. 26.

42 Insbesondere die Zahl der Rumänisch-Orthodoxen Christen stieg erheblich in jüngster Zeit durch den Beitritt Rumäniens zur EU. Vgl. Statistik Austria 2014, S. 26. 43 Statistik Austria 2002, S. 20. Auch bei Muslimen hat ungefähr die Hälfte der Gesamtanzahl die österreichische Staatsbürgerschaft. Vgl. Heine / Lohlker / Potz 2012, S. 20. 44 Vgl. Marik-Lebeck 2010, S. 6. 
Herkunft ist, gefolgt von Rumänen, Bulgaren, Russen, Griechen und Angehörigen anderer Nationen. ${ }^{45}$

Da in Österreich die allgemeine Wehrpflicht für alle männlichen Staatsbürger vom 17. bis zum 50. Lebensjahr gilt, und Wehrpflichtige bis zum 35. Lebensjahr zum Grundwehrdienst eingezogen werden können, traten seit den 80er Jahren immer mehr Staatsbürger mit nicht-katholischer Religion in den Dienst des österreichischen Bundesheers. Dadurch stellte sich für das österreichische Bundesheer die Frage wie die Religionsausübung dieser Soldaten in der Armee gewährleistet werden sollte. ${ }^{46}$ Interessanterweise wurde ein erster Erlass 1993 für strenggläubige Angehörige der Glaubensgemeinschaft der Sikhs herausgegeben, dann erst folgten 1998 zwei Erlässe für nicht strenggläubige und für strenggläubige muslimische Soldaten. ${ }^{47}$ Es folgte ein Erlass für besonders strenggläubige orthodoxe Angehörige der israelitischen Kultusgemeinde und der islamischen Glaubensgemeinschaft und 2002 eine gesonderte Regelung hinsichtlich der Barttrageerlaubnis für besonders strenggläubige Angehörige der islamischen Glaubensgemeinschaft. ${ }^{48}$ Einen Erlass für orthodoxe Soldaten gab es nicht. 2003 wurden alle diese Spezialregelungen in einem einzigen Erlass zusammengefasst und im Verlautbarungsblatt I des Bundesministeriums für Landesverteidigung veröffentlicht (VB1. I, Nr. 49/2003). Dieses wurde 2006 revidiert (VB1. I, Nr. 53/ 2006). ${ }^{49}$ Darin sind die besonderen Bestimmungen für Soldaten von sieben Religionsgemeinschaften geregelt: die für die Altkatholische Kirche, die Evangelische Kirche A.B. und H.B, die Evangelisch-Methodistische Kirche, die Islamische Glaubensgemeinschaft, die Israelitische Religionsgesellschaft, die Kirche der Siebenten-Tags-Adventisten sowie die Glaubensgemeinschaft der Sikhs. Von diesen Regelungen waren im Jahr 2008 insgesamt 18.000 Grundwehrdiener und Personen im Ausbildungsdienst betroffen. ${ }^{50}$

Auffällig ist hierbei, dass es spezielle rechtliche Regelungen für kleinere evangelische Gruppierungen, für die Sikhs und für die Juden gab, aber keine

45 Vgl. http://medienservicestelle.at/migration_bewegt/2014/01/02/rund-500-000-or thodoxe-christinnen-in-osterreich/, letzter Aufruf 19.5.2015.

46 Vgl. Hanak 1992.

47 Vgl. Trauner 2009a, S. 5.

48 Trauner 2009a.

49 Zitat nach Trauner 2009a, S. 4.

50 Diese Regelungen gelten nur für Präsenzdienstleistende, d.h. vor allem für Grundwehrdiener (GWD), die aufgrund der allgemeinen Wehrpflicht einberufen werden und für „Personen im Ausbildungsdienst“ (PiAD), die ein längeres Dienstverhältnis anstreben. Keine Regelungen gibt es für Berufssoldaten, die in Österreich entweder den Status von Beamten oder Vertragsbediensteten haben. Sie gelten zudem nur im Normdienst und zum Beispiel nicht bei Einsätzen. Allerdings können Beamte und Vertragsbedienstete teilweise an den Regelungen für Grundwehrdiener und PiADs optional partizipieren. So Trauner 2009a, S. 7. 
Regelungen für orthodoxe Christen, obwohl diese nach dem Zensus von 2001 immerhin 2,2 \% der österreichischen Bevölkerung ausmachen und die viertgrößte Religionsgemeinschaft in Österreich darstellen,$^{51}$ zumal für die griechisch-orientalischen Kirche (orthodoxen) Kirche in Österreich seit der Verabschiedung des „Orthodoxengesetzes“ von 1967 dieselben Möglichkeiten offenstanden wie der Evangelischen Kirche A.B. und H.B. ${ }^{52}$ Erst am 1.7.2011 wurde eine Vereinbarung mit der orthodoxen Bischofskonferenz zur Einführung einer orthodoxen Militärseelsorge unterzeichnet. Eingesetzt wurde der orthodoxe Priester Dr. Alexander Lapin. ${ }^{53}$ Er betreut in ehrenamtlicher Funktion die ca. 250 orthodoxen Soldaten in Wien, die 15 verschiedenen orthodoxen Kirchen angehören.$^{54} \mathrm{Zu}$ seinen Aufgaben gehören die berufsethische Bildung, die Gestaltung des lebenskundlichen Unterrichts und die seelsorgerliche Betreuung, insbesondere in persönlichen Krisensituationen. Die Feier einer göttlichen Liturgie wurde jedoch explizit in seinem Dienstvertrag ausgeklammert. ${ }^{55}$ Für seine Tätigkeit bekommt er im Rahmen eines Werkvertrages eine Aufwandsentschädigung. Da er die Aufgaben neben seinem Beruf ausübt, kann er in der Regel nur einmal pro Woche bzw. am Wochenende seine Aktivitäten in Wien entfalten. Seine Tätigkeit unterscheidet sich hinsichtlich seines Status insoweit schon erheblich von dem der katholischen oder evangelischen Seelsorger, die hauptamtlich in der Militärseelsorge tätig sind. ${ }^{56}$

\subsection{Die religiöse Kategorisierung der Soldaten im österreichischen Bundesheer}

Das österreichische Bundesheer teilt die Angehörigen von Religionsgemeinschaften prinzipiell in drei Kategorien ein: a) in bloße „Angehörige“ bzw. in „nicht strenggläubige Angehörige“, b) in „strenggläubige Angehörige“ und c) in

51 Vgl. Trauner 2009a, S. 14.

52 Im $\$ 7$ des Orthodoxengesetzes wurde festgelegt, dass die Paragraphen zur Regelung der Militärseelsorge, Krankenseelsorge und Gefangenenseelsorge des Protestantengesetzes von 1961 „,sinngemäß“ auch für die griechisch-orientalische Kirche gelten. Die gleiche Formulierung wurde im $\S 2$ des Kirchengesetzes für die Orientalisch-Orthodoxen Kirchen 2003 getroffen. Bisher wurden aber keine Sonderbestimmungen für orientalisch-orthodoxe Christen erlassen.

53 Vgl. http://www.bundesheer.at/organisation/regional/common/artikel.php?region= wien \&ID=7619, letzter Aufruf 1.5.2015.

$54 \mathrm{Vgl}$. http://www.bundesheer.at/cms/artikel.php?ID=5808, letzter Aufruf 2.5.2015.

55 So der Geistliche Alexander Lapin 2011 im Interview mit Karl-Heinz Leitner (http://www.dersoldat.at/orthodoxe-militaerseelsorge-im-oebh?PHPSESSID=3ctsdp9 epl2f3or8k5jrmpehr4, letzter Aufruf 2.5.2015).

56 Telefonat mit Dr. Alexander Lappin am 4.5.2015. Vgl. a. das Video „Orthodoxe Militärseelsorge. Militärseelorger Dr. Alexander Lapin im Interview“ (http://www.or thodoxe-kirche.at/site/orthodoxesleben/militaerseelsorge, letzter Aufruf 19.5.2015). 
„besonders strenggläubige Angehörige“. Diese Terminologie ist nach Militärsuperintendent Trauner mit den Vertretern der Islamischen und Israelitischen Religionsgemeinschaft akkordiert worden. ${ }^{57}$ Allerdings wird diese Dreiteilung nicht bei allen Religionsgemeinschaften angewandt. Bei Soldaten der evangelischen Kirchen, der Altkatholischen Kirche und der Methodistischen Kirche gibt es nur die Kategorie der normalen Angehörigen; bei den Sikhs gibt es ausschließlich die Kategorie der Strenggläubigkeit, d.h. es wird davon ausgegangen, dass jeder Sikh auch seine Religion streng praktiziert, dass es aber andererseits keine besondere Strenggläubigkeit gibt. Bei Juden gibt es die Unterscheidung von bloßen Angehörigen der jüdischen Religion und den „strenggläubigen“ Juden. Nur bei Muslimen werden alle drei Kategorien voll angewandt. ${ }^{58}$

Die Einstufung erfolgt bei Juden und Muslimen durch eine schriftliche Bescheinigung durch die offiziellen staatlichen Vertretungen ohne weitere Prüfung. ${ }^{59}$ Bei den Sikhs erfolgt die Überprüfung der Strenggläubigkeit in Ermangelung einer offiziellen Vertretung durch den Kommandanten des Bataillons, bei dem sie einrücken: Wenn der Rekrut die äußerlichen Erkennungsmerkmale des Khalsa befolgt (ungeschorene Haare und Bart, Kamm, Armreif, Dolch und kurze Hosen) ist er als streng gläubig einzustufen. ${ }^{60}$ Die Feststellung der Strenggläubigkeit bzw. besonderen Strenggläubigkeit hat in der Regel die Einberufung zum Militärkommando Wien zur Folge. ${ }^{61}$ Hier haben die Soldaten einen Rechtsanspruch auf die Einhaltung der jüdischen bzw. islamischen Speiseregeln. Die

57 Trauner 2009a, S. 12; Trauner 2009b, S. 24.

58 Vgl. Trauner 2009a, S. 13.

59 Trauner 2009b, S. 24. Um eine solche Bescheinigung zu erhalten muss der Rekrut der Islamischen Glaubensgemeinschaft gegenüber in einer „Verpflichtungserklärung“ mitteilen, wann er in die Islamische Glaubensgemeinschaft gekommen ist und folgende Erklärung unterzeichnen: „Dort wurde ich von dem zuständigen Organ der Gemeinschaft über meine religiösen Pflichten, insbesondere über die strenge Beobachtung der Gebote und Verbote der islamischen Religion (tägliche Gebete, Freitagsgebet, Fasten im Monat Ramadan, Schweinefleischverbot, Alkoholkonsumverbot, etc.), als praktizierender Moslem belehrt. Ich habe mich dem obgenannten Organ der Gemeinschaft gegenüber zu einer strikten Einhaltung der vorstehend erwähnten religiösen Vorschriften während meiner Militärdienstzeit verpflichtet erklärt." Vgl. http://www.derislam.at/der admin/formulare/iggioe/iggioe-002-verpflichtungserklärung\%20für\%20rekruten.pdf, letzter Aufruf 1.5.2014.

60 Trauner 2009b, S. 24.

61 Vgl. Trauner 2009a, S. 25. Trauner 2009b, S. 24. Es besteht allerdings das Problem, dass sich mittlerweile fast alle Muslime als strenggläubig definieren. Da die Zahl der muslimischen Präsenzdiener zugleich ständig zunimmt, es aber in anderen Bundesländern einen Mangel an Präsenzdienern gibt, gibt es Schwierigkeiten die Einberufung für alle zu realisieren. Vgl. http://www.genios.de/presse-archiv/artikel/FURC/20090917/be sondere-baerte-muslime-im-oesterr/0700850820670720690952009\% 2009171736000047. html, letzter Aufruf 3.5.2015. 
Muslime können zudem das Freitagsgebet in einer Moschee auf dem Kasernengelände durchführen, was einzigartig in ganz Europa ist. An anderen Standorten bemüht man sich zwar ebenfalls darum, die religiösen Speisevorschriften zu berücksichtigen und Möglichkeiten zu geben, am Freitagsgebet teilzunehmen, allerdings gibt es keinen Rechtsanspruch hierfür. Bei Angehörigen christlicher und anderer Religionsgemeinschaften wird keine Einstufung der Frömmigkeit vorgenommen.

Die Sonderregelungen für religiöse Minderheiten sind als Abweichungen von einer Norm formuliert, die nach Trauner von einem katholischen Soldaten als „Normalbedienstetem“ ausgeht, der nicht streng gläubig ist. ${ }^{62}$ Es gibt zwar auch Regelungen für besonders streng gläubige Christen; darunter werden aber diejenigen verstanden, die ein geistliches Amt innehaben bzw. sich darauf vorbereiten. Diese sind von der Stellungs- und Wehrpflicht befreit. Bei den christlichen Minderheiten geht man davon aus, dass sie nur punktuell auf ihre konfessionellen Proprien Wert legen, aber ansonsten dem katholischen „Normalbediensteten“ entsprechen. ${ }^{63}$

\subsection{Bereiche der Regelungen für religiöse Minderheiten}

\subsubsection{Dienstfreistellung}

Die Zeitordnung der Normaldienstzeit ist durch das katholische Christentum, die Mehrheitsreligion in Österreich, geprägt. Sie gilt bis auf Ausnahmen für alle, also auch für Konfessionslose: Sonntage sind für alle frei unabhängig von ihrer Zugehörigkeit zu einer Religion. Alle gesetzlichen Feiertage außer dem 1. Mai und dem Nationalfeiertag (26. Oktober) haben christlich geprägten Charakter. Juden, Muslime und Menschen ohne Bekenntnis partizipieren insoweit an den christlichen Feiertagen wie z.B. Weihnachten, Ostern oder Pfingsten, sofern sie sich nicht bewusst dagegen entscheiden, an diesen Tagen Dienst zu tun. Ebenso partizipieren z. B. evangelische Christen an den katholischen Feiertagen Fronleichnam, Mariä Empfängnis, Mariä Himmelfahrt oder Allerheiligen, obwohl sie die meisten mit diesen Festen verbundenen theologischen Aussagen ablehnen. Freistellungen für religiöse Feste von Minderheiten werden in der Regel zusätzlich zu den katholisch geprägten Feiertagen in Sonderregelungen gewährt. Damit es für Angehörige von religiösen Minderheiten nicht zu einer ungerechten Erhöhung der freien Tage kommt, müssen die Soldaten stattdessen vermehrt Dienste an Sonntagen bzw. an christlich geprägten Feiertagen übernehmen (Ausnahme: Karfreitag und Versöhnungstag). ${ }^{64}$

62 Trauner 2009a, S. 18.

63 Vgl. Trauner 2009a, S. 19.

64 Vgl. Trauner 2009a, S. 19-10; Trauner 2009b, S. 19, 23. 
Strenggläubigen jüdischen und muslimischen Soldaten ist es nach dem Erlass von 2006 erlaubt, die täglichen Gebete individuell durchzuführen. ${ }^{65}$ Ebenso gilt dies für die Gebetszeiten der Sikhs. Im Alltag betrifft dies jedoch nur die Mittagsbzw. Nachmittagsgebete, da nur diese in die normale Dienstzeit fallen. Hierfür werden in der Regel 10 Minuten zur Verfügung gestellt. ${ }^{66}$ Die Gebetszeiten greifen kaum in die normale Dienstzeit ein, zumal eine Zusammenlegung von Gebetszeiten in Ausnahmefällen beim sunnitischen Islam möglich und im schiitischen Islam die Regel ist. Die Feiertagsregelungen greifen sehr viel stärker in die Dienstpläne ein. Hier gelten folgende Regelungen:

1. Evangelische, altkatholische und methodistische Kirche

- Da der Sonntag und die meisten christlichen Feiertage sowieso in der normalen Dienstzeitregelung berücksichtigt sind, bedarf es nur zu einem geringen Teil einer besonderen Regelung für die Freistellung der evangelischen Minderheiten.

- Angehörige der evangelischen, der altkatholischen und der methodistischen Kirchen werden am Karfreitag allerdings verpflichtend vom Dienst freigestellt, ohne diesen Tag einarbeiten zu müssen.

- Darüber hinaus wird ihnen obligatorisch am Reformationstag der Besuch eines Gottesdienstes eingeräumt.

2. Kirche der Siebenten-Tags-Adventisten

- Soldaten, die der Kirche der Siebenten-Tags-Adventisten angehören, kann jede Woche der Besuch eines Gottesdienstes am Samstag ermöglicht werden. Der Besuch muss bei Gewährung eingearbeitet werden. Dies ist jedoch kaum relevant, da samstags in der Regel sowieso kein Dienst zu verrichten ist.

3. Religionsgemeinschaft der Sikhs

- Sikhs haben keinen heiligen Wochentag. Nur am ersten Tag des indischen Mondkalenders ist es üblich, den Gurdwara zu besuchen. Wichtiger Feiertag ist der Geburtstag des Guru Nanak.

- Sikhs kann auf Antrag an diesen oder weiteren Tagen Dienstfreistellung im Rahmen des sogenannten „Bittrapports“ gewährleistet werden. Darauf besteht jedoch kein rechtlicher Anspruch und es besteht die Pflicht zur Einarbeitung an anderen Tagen.

65 Bundesministerium für Landesverteidigung 2006, Abschnitt I, 7 und II, 5.

66 Vgl. Trauner 2009b, S. 26 f. 
4. Islamische Glaubensgemeinschaft

- Muslime, die als normale „Anhänger“ der islamischen Religion eingestuft werden, haben keinen Rechtsanspruch auf die Dienstfreistellung am Freitag, für die Durchführung der Pflichtgebete oder für das Freitagsgebet oder an islamischen Feiertagen.

- Strenggläubig bzw. besonders strenggläubig eingestuften Muslimen werden 3 Tage am Ramadanfest (Id al-Fitr) und 4 Tage am Opferfest (Id al-Adha) freigestellt. Während für Grundwehrdiener und für Personen im Ausbildungsdienst dies verpflichtend ist, ist es für Bundesbedienstete nur eine KannVorschrift. Beide haben die freigestellte Dienstzeit einzuarbeiten. ${ }^{67}$

5. Israelitische Religionsgesellschaft

- Alle Mitglieder der israelitischen Religionsgesellschaft haben ein Recht darauf, am Sabbat und am Versöhnungstag (ohne Einarbeitung) vom Dienst befreit zu werden.

- Beamten und Vertragsbediensteten kann darüber hinaus nach Dienstzulässigkeit das Einarbeiten folgender Feiertage genehmigt werden: Pässah-Fest (2 Tage am Anfang und 2 Ende des Festes), Wochenfest (2 Tage), Neujahrsfest (2 Tage), Laubhüttenfest (2 Tage).

- Strenggläubigen jüdischen Grundwehrdienern und Personen im Ausbildungsdienst ist die Freistellung an diesen Festtagen verpflichtend zu gewähren. Darüber hinaus können sie an folgenden Festen vom Dienst befreit werden: Schlussfest (1 Tag), Thorafreudenfest (1 Tag). ${ }^{68}$ Die Tage sind allerdings einzuarbeiten. $^{69}$

6. Orthodoxe Kirchen

- Für orthodoxe oder orientalisch-orthodoxe Christen gibt es bisher keine $o b$ ligatorischen Dienstfreistellungen für orthodoxe Feste.

- Allerdings können sie auf Antrag für die hohen Feste wie Weihnachten, Ostern und für den Sonntag der Orthodoxie auf Antrag freigestellt werden. Die Tage müssen eingearbeitet werden. ${ }^{70}$

67 Vgl. Trauner 2009b, S. 26.

68 So Bundesministerium für Landesverteidigung 2006, Abschnitt I, 7.

69 Vgl. Trauner 2009b, S. 25.

70 Vgl. Trauner 2009a, S. 33. 


\subsubsection{Verpflegung}

Bei der Verpflegung muss grundsätzlich zwischen Bundesbediensteten und Grundwehrdienern bzw. Personen im Ausbildungsdienst unterschieden werden, die als strenggläubig eingestuft werden. Während streng religiöse jüdische und muslimische Präsenzdiener das Anrecht auf eine kostenlose Verpflegung unter Berücksichtigung der religiösen Speisevorschriften haben, haben dies Beamte und Vertragsbedienstete nicht. Sie haben nur die Berechtigung gegen Bezahlung an der eventuell vorhandenen Truppenverpflegung zu partizipieren, die religiöse Speisevorschriften berücksichtigt - sofern diese angeboten wird. Jüdische und muslimische Grundwehrdiener, die als bloße Anhänger eingestuft sind, haben ebenfalls nur eine optionale Berechtigung, daran teilzunehmen. ${ }^{71}$ Dies hat zur Folge, dass sich Muslime, die sich vielleicht nicht als besonders strenggläubig betrachten, aber dennoch kein Schweinefleisch essen wollen, lieber als strenggläubig deklarieren.

\section{a. Juden}

Koschere Kost - bei der nicht nur auf Schweinefleischprodukte verzichtet werden muss, sondern auch fleisch- und milchhaltige Speisen getrennt und mit separatem Geschirr gereicht werden muss - kann prinzipiell strenggläubigen jüdischen Soldaten entweder durch eine Catering-Firma in die Kaserne geliefert werden oder es wird den Soldaten eine Infrastruktur zur Zubereitung einer koscheren Kost mit getrenntem Geschirr zur Verfügung gestellt. ${ }^{72}$

\section{b. Muslime}

Grundwehrdiener und Personen im Ausbildungsdienst haben, wenn sie strenggläubig oder besonders streng gläubig eingestuft sind, ein Anrecht auf eine schweinefleischlose und alkoholfreie Kost. Die Bereitstellung einer solchen Kost gehört heute zum Standard innerhalb der Maria-Theresien-Kaserne in Wien. Allerdings bemüht man sich auch in anderen Kasernen, dies zu gewährleisten, weil nicht allen Muslimen die Einberufung in das Militärkommando Wien gestattet werden kann und weil auch Muslime, die sich nicht als strenggläubig definieren, meist eine schweinefleischlose Kost bevorzugen. Allerdings handelt es sich dabei nicht um halal geschlachtetes Fleisch ${ }^{73}$, weshalb sie von manchen Muslimen nicht gegessen wird.

71 Vgl. Trauner 2009a, S. 24.

72 Teilweise wurde früher auch jüdischen Soldaten erlaubt, ein koscheres Gasthaus zu besuchen. Dies ist allerdings heute nicht mehr üblich. Vgl. Trauner 2009a, S. 27.

73 Vgl. Trauner 2009a, S. 27. 
c. Sikhs

Die Einhaltung der religiösen Speisegebote der Sikhs ist nicht obligatorisch. Soweit sie kein Rinderfleisch essen oder Vegetarier sind, versucht man „nach Dienstesmöglichkeiten “ ihnen entgegenzukommen, indem man bei der normalen Kost das Rindfleisch weglässt oder ganz auf vegetarische Kost umstellt. ${ }^{74}$

d. Christliche Minderheiten

Für christliche Minderheiten gibt es bisher keine Sonderregelungen im Blick auf die Verpflegung. Dies obwohl der orthodoxe Festkalender sehr genaue Fastenvorschriften enthält und zum Teil vegane Ernährung vorschreibt, zum Teil auch die Enthaltung von Ölen. Das Bewusstsein strengen Fastens scheint bei vielen orthodoxen Soldaten aber nicht ausgeprägt $\mathrm{zu}$ sein und durch das Prinzip kath'oikonomian ist auch eine theologische Rechtfertigung gegeben, die das Abweichen von den Fastenregeln erlaubt. ${ }^{75}$

\subsubsection{Bekleidung}

a. Christen

Für Christen gibt es (außer für katholische und orthodoxe Priester) keine besonderen Kleidungsvorschriften. Daher gibt es auch keine speziellen Regelungen.

b. Juden

Strenggläubigen Juden ist das Tragen der Kippa unter der militärischen Kopfbedeckung erlaubt. ${ }^{76}$

c. Sikhs

Die Sikhs konnten bereits 1993 die Genehmigung zum Tragen unbeschnittener Bart- und Kopfhaare erhalten, da sie nachweisen konnten, dass dies zu den religiösen Pflichten eines strenggläubigen Sikhs gehört. Anstelle der üblichen militärischen Kopfbedeckung können sie einen Turban tragen. Infolgedessen sind sie für bestimmte Ausbildungsgänge, bei denen das Tragen eines Helms notwendig

74 Vgl. Trauner 2009a, S. 32.

75 Telefonat mit Dr. Alexander Lapin, 4.5.2015. Allerdings gibt es auch im Judentum und Islam zahlreiche Ausnahmen von den Fastenregeln, wenn diese aus äußeren Gründen nicht eingehalten werden können.

76 Bundesministerium für Landesverteidigung 2006, Abschnitt II, 5. 
ist, ausgeschlossen. Zudem sind sie vom Tragen einer Sicherheitsmaske und der damit verbundenen Dichtheitsprüfung befreit. ${ }^{77}$

\section{d. Muslime}

Für bloße Anhänger der islamischen Religion sowie für strenggläubige Muslime gibt es keine besonderen Kleidungsvorschriften. Allerdings wurde 2002 eine Regelung eingeführt, die es „,besonders strenggläubigen“ Muslimen erlaubt, einen Bart zu tragen. Dies muss jedoch fallweise beim Bundesministerium für Landesverteidigung beantragt werden. Falls eine Erlaubnis erteilt wird, hat dies zur Folge, dass die Soldaten vom Tragen einer Schutzmaske und der Dichtheitsprüfung befreit sind. ${ }^{78}$

\subsubsection{Orte und Umfang der Militärseelsorge}

\section{a. Katholische Militärseelsorge}

Die katholische Kirche ist an fast allen Standorten mit offiziellen Büros der katholischen Militärseelsorge, mit hauptamtlichen geistlichen Amtsträgern und mit Kirchen und Kapellen in den Kasernen und militärischen Liegenschaften vertreten. ${ }^{79}$ Die Tätigkeiten der katholischen Militärseelsorge wurden 2013 in umfassenden Leitlinien beschrieben und beinhalten Sonntagsmessen, das Stundengebet, die Firmung, Trauungen, Krankensalbung und Bestattungsfeiern, Wallfahrten und Segnungen. Die Militärseelsorge bietet auch Möglichkeiten der Glaubensvertiefung und Evangelisierung. Die Betreuung und Entfaltung der katholischen Militärseelsorge ist also umfassend und betrifft alle Bereiche des kirchlichen Lebens. ${ }^{80}$

\section{b. Evangelische Militärseelsorge}

Das Tätigkeitsfeld der evangelischen Militärseelsorge ist der katholischen ähnlich. Auch wenn die Zahl der evangelischen Soldaten bei weitem geringer ausfällt, so ist doch auch die evangelische Militärseelsorge an den meisten Standorten mit hauptamtlichen und nebenamtlichen Militärseelsorgern vertreten. Sie bietet regelmäßig Gottesdienste an, begleitet die evangelischen Soldaten mit Taufe, Konfirmation, Trauung und Beerdigung an wichtigen Wendepunkten des Lebens.

77 Bundesministerium für Landesverteidigung 2006, Abschnitt V, 4.

78 Trauner 2009a, S. 31; Trauner 2009b, S. 27.

79 Vgl. http://www.bundesheer.at/organisation/beitraege/mil_seelsorge/kath_ms/kon takt.shtml, letzer Aufruf 3.5.2015.

$80 \mathrm{Vgl}$. http://www.bundesheer.at/organisation/beitraege/mil_seelsorge/kath_ms/pdf/ pastorale_leitlinien.pdf, letzter Aufruf 3.5.2015. 
Bis heute fehlt der evangelischen Militärseelsorge allerdings ein eigener gottesdienstlicher Raum. Die evangelischen Gottesdienste für Soldaten finden im Wiener Raum normalerweise in der evangelischen Auferstehungskirche im 7. Bezirk statt. Sie wird deshalb bisweilen als neue evangelische Garnisonkirche bezeichnet. ${ }^{81}$ Der Staat besoldet die Pfarrer, finanziert die Aktivitäten und stellt Büros und Sachdienstleistungen zur Verfügung. Die Kirche ist für die Finanzierung nebenamtlicher Militärpfarrer und laufende Anschaffungen zuständig. ${ }^{82}$

\section{c. Die orthodoxe Militärseelsorge}

Den orthodoxen Christen im österreichischen Militär steht nach §7 des Orthodoxengesetzes von 1967 eine Militärseelsorge zu, die mit der der Protestanten vergleichbar ist. D.h. dass der Bund die Ausübung der Seelsorge an den orthodoxen Angehörigen des Bundesheeres zu gewährleisten hat und die für die orthodoxe Militärseelsorge erforderlichen Personal- und Sachaufwand in ausreichendem Maße bereitzustellen hat. Die Gewährleistung hat auf der Basis der demographischen Entwicklungen der orthodoxen Kirche zu erfolgen. ${ }^{83}$ Es dauerte jedoch fast ein halbes Jahrhundert bis eine orthodoxe Militärseelsorge tatsächlich eingerichtet wurde, nun allerdings mit gänzlich anderen Rahmenbedingungen. Die orthodoxe Militärseelsorge wird nicht mehr als Aufgabe des Staates angesehen, sondern als Recht für die Orthodoxe Kirche eingeräumt. Eine Infrastruktur wird so gut wie nicht zur Verfügung gestellt - wenn man von Diensttelefon, Einrichtung einer Postadresse und einer Webseite absieht. ${ }^{84}$ Erst 2015, nach 4 Jahren, bekam der zuständige Priester ein Büro zugewiesen. Der orthodoxe Priester ist nicht Angehöriger des Bundesheeres, trägt auch keine Uniform und hat innerhalb des Bundesheeres nur geringe Rechte. Die Finanzierung der Tätigkeit muss über die orthodoxe Kirche erfolgen. ${ }^{85}$ Er bekommt lediglich eine geringfügige Aufwandsentschädigung. ${ }^{86}$ Dabei sind die Aufgaben der orthodoxen Seelsorge ähnlich umfassend wie die der römisch-katholischen und evangelischen Seelsorge. Er begleitet Soldaten, führt Gottesdienste, rituelle Handlungen (z. B. Wasserweihe) durch und beteiligt sich am lebenskundlichen Unterricht. Eine Betreuung von orthodoxen Soldaten an anderen Standorten

81 Es ist allerdings darauf hinzuweisen, dass die evangelische Militärseelsorge bereits eine eigene Garnisonskirche hatte. Es war die ehemalige Schwarzpanierkirche (Ecke Schwarzspanierstraße/Garnisiongasse), die 1861 gemäß kaiserlichem Dekret für die Abhaltung von Gottesdiensten der Evangelischen Kirchen A.B. und H.B. umgewidmet, allerdings im zweiten Weltkrieg zerstört wurde.

82 Trauner 2012, S. 183.

83 Dies wurde ebenfalls in $\$ 7$ des Orthodoxengesetzes festgehalten.

84 So Trauner 2012, S. 192.

85 Trauner 2012, S. 192.

86 Trauner 2012, S. 192. 
außerhalb Wiens ist kaum möglich, da der Priester alleine ist und die Aufwandsentschädigung regelmäßige Fahrtkosten nicht abdeckt. Eine orthodoxe Kirche auf Kasernengelände gibt es im Unterschied zu einer Moschee bisher nicht. Eine göttliche Liturgie, die ebenso wie für das katholische auch für das orthodoxe Verständnis von zentraler Bedeutung ist, konnte bisher nicht innerhalb von Militärstandorten durchgeführt werden.

\section{d. Die islamische Militärseelsorge}

Eine professionelle islamische Militärseelsorge ist bereits seit längerer Zeit in Vorbereitung. Ab 2004 gab es intensivere Überlegungen, doch erst mit der Verabschiedung des neuen Islamgesetzes 2015 war Grundlage für einen Vertragsabschluss für einen islamischen Militärseelsorger gegeben. Im neuen Islamgesetz wird in $§ 11$ der islamischen Religionsgemeinschaft das Recht eingeräumt, Muslime im Bundesheer zu betreuen.$^{87} \mathrm{Im}$ Vergleich dazu ist es im Protestantengesetz von 1961 (und daran anschließend im Orthodoxengesetz von 1967) der Staat selbst, der sich zur Einführung der Militärseelsorge inklusive Übernahme der finanziellen Kosten für Personal und Sachmittel ,in ausreichendem Maß“ verpflichtet. ${ }^{88}$ Es ist also damit zu rechnen, dass auch der islamischen Seelsorge auf Dauer kein ebenbürtiger Status zur evangelischen und katholischen Seelsorge eingeräumt wird. Vermutlich werden wie bei dem orthodoxen Seelsorger nur Dienstverträge mit Aufwandsentschädigungen abgeschlossen, die die Kosten kaum decken und eine zeitliche Präsenz nur sehr eingeschränkt zulassen. ${ }^{89} \mathrm{Am}$ 19.6.2015 wurde eine gesetzliche Regelung für die „Religiöse Betreuung für Angehörige des Bundesheeres" erlassen, die am 22.7.2015 nochmals revidiert wurde. Darin wird festgehalten, dass die Militärimame von der Islamischen Glaubensgemeinschaft ausgewählt, entsandt und vom BMLV nach einer Verlässlichkeitsprüfung bestätigt werden. Sie stehen aber explizit nicht in einem Dienstverhältnis zur Republik Österreich und sind keine Soldaten. Die Gültigkeit der Dienstregelungen von 2006 inklusive der Regelung für den Nachweis der Strenggläubigkeit werden nochmals bestätigt. ${ }^{90}$ Allerdings konnten in räumlicher Hinsicht bereits Lösungen gefunden werden, die nicht nur für Österreich, sondern für ganz Europa einzigartig sind: 2002 wurde in einem leer stehenden Gebäude der Maria Theresien-Kaserne ein kleiner Gebetsraum hergerichtet und am

87 Islamgesetz $\$ 11$ Abs. 1.1.

88 Vgl. $\$ 17$ Abs. 1 des Protestantengesetzes.

89 Trauner weist zu Recht in seinem Beitrag darauf hin, dass sich mit diesen neuen Regelungen für orthodoxe und islamische Seelsorge um einen Paradigmenwechsel des Verhältnisses zwischen Staat und Religionen handelt, bei dem in Zukunft vermutlich auch die Finanzierung der katholischen und evangelischen Militärseelsorge in Frage gezogen werden könnte. Vgl. Trauner 2012, S. 193, 196.

90 Bundesministerium für Landesverteidigung 2015. 
20.2.2004 feierlich eröffnet. 2006 ging man daran, einen zweiten größeren Raum (ca. $70 \mathrm{~m}^{2}$ ) im selben Gebäude zu einer Moschee umzubauen. Darüber hinaus wurde ein Büroraum für künftig anzustellende islamische Seelsorger bereits geschaffen. Durch diese Ausstattung hat die Maria-Theresien-Kaserne einen Vorbildcharakter in Europa, denn bisher gibt es in keiner europäischen Armee Moscheen innerhalb von Kasernen. ${ }^{91}$

e. Andere Religionsgemeinschaften und Betreuung von nicht-religiösen Soldaten

Für andere Religionsgemeinschaften wie z. B. die Sikhs oder für christliche Kirchen, für die es teilweise in den Erlassen besondere Regelungen im Blick auf die Dienstfreistellung oder hinsichtlich der Verpflegung und Bekleidung gibt, existieren weder besondere Räumlichkeiten noch Überlegungen zur seelsorgerlichen Betreuung. Auch gibt es keine Konzepte hinsichtlich einer sozialen und psychologischen Betreuung von Soldaten, die nicht religiös sind und sich keiner Religionsgemeinschaft zuordnen.

\section{Der Umgang mit religiösen Minderheiten in der österreichischen Armee aus religionswissenschaftlicher Perspektive}

Die Religionswissenschaft setzt sich zum Ziel, Religionen entsprechend ihrem eigenen Selbstverständnis unter gleichzeitiger Wahrung kritischer Distanz und methodischem Agnostizismus darzustellen. Sie ist nicht Fürsprecher für bestimmte Religionsgemeinschaften und beurteilt nicht, was sie lehren oder was sie als letzte Wahrheiten erachten, achtet aber darauf, dass Religionen nicht verzerrt dargestellt, vorgezogen oder benachteiligt werden. Auf der Basis der allgemeinen Menschenrechte setzt sie sich dafür ein, dass Gläubigen aller Religionen ermöglicht wird, in verschiedensten Kontexten ihre Religion entsprechend ihren Lehren ausüben können. Dies impliziert auch das Recht, sich teilweise oder ganz von einer Religion abzuwenden, keiner Religion nachzugehen bzw. einer Religion anzugehören. Es gibt ein Recht, aber keine Pflicht zur Religionsausübung.

Dies trifft sich in weiten Teilen mit den Prinzipien des modernen säkularen Staates, der sich ebenso auf eine Gleichbehandlung und Äquidistanz zu Religionsgemeinschaften verpflichtet und auf eine Beurteilung von letzten Wahrheiten und Kontrolle der Religionsausübung verzichtet, zum anderen aber auch mit neueren ethischen und organisationsstrategischen Konzeptionen in der Wirtschaft, in der der professionelle Umgang mit religiöser und kultureller Diversität zunehmend als Qualitätsmerkmal erkannt wird. Gemäß $\$ 43$ Abs. 4 des österrei-

91 Vgl. Sladek 2011. 
chischen Wehrgesetzes gilt für jeden Soldaten (im Unterschied zu parteipolitischer Agitation): „Eine religiöse Betätigung darf jedoch nicht geschmälert werden." Es erfolgt keine Einschränkung auf bestimmte Religionsgruppen, Berufsgruppen oder Personen, auch keine Bevorzugung bestimmter Religionsgemeinschaften, Teile religiöser Gemeinschaften oder eine Reduktion auf bestimmte rituelle Handlungen, aber auch keine Verpflichtung zu irgendwelchen Handlungen. Im Folgenden soll untersucht werden, inwieweit das Heer diesem Grundsatz entspricht, keine Schmälerung religiöser Betätigung für die verschiedensten Religionsgemeinschaften unter Wahrung des Prinzips der Gleichbehandlung feststellbar ist, inwieweit ein professioneller Umgang mit religiöser Diversität zu erkennen ist, der sich in Vorschriften, Planung, Strukturen und Finanzen niederschlägt, inwieweit religiöse Gruppen entsprechend ihrem Selbstverständnis dargestellt werden und den religiösen Bedürfnissen von Soldaten Rechnung getragen wird. Hilfreich ist dabei ein historischer Vergleich, denn obwohl die katholische Kirche im 19. Jh. noch eine privilegierte Stellung in Österreich gegenüber anderen Religionen hatte, wurden in der k. u. k. Armee bereits erste Grundlagen zur Berücksichtigung dieser Prinzipien geschaffen. Die Armee spielte insoweit eine Vorreiterrolle im Hinblick auf einige Prinzipien, die erst viel später in der gesamten Gesellschaft übernommen wurden. Mir scheint allerdings, dass derzeit die Tendenz eher dahin geht, professionelle Strukturen der Betreuung abzubauen und die organisatorische Einbindung im Heer zu reduzieren.

\subsection{Historischer Vergleich: Der Umgang in der k. u. k. Armee und im österreichischen Bundesheer}

Vergleicht man den Umgang mit religiösen Minderheiten in der k. u. k. Armee mit dem im österreichischen Bundesheer der Gegenwart, so fällt zunächst auf, dass die Regelungen zur Zeit der Donaumonarchie umfassender waren und dass die Militärseelsorge an religiösen Minderheiten eine sehr viel größere Dimension hatte - es gab nicht nur einen oder zwei Seelsorger für Minderheiten, sondern für Juden, Muslime, Orthodoxe und Evangelische jeweils ca. 2-10, in Kriegszeiten sogar 50-100 Seelsorger. Dies mag zum einen mit der Größe des Reiches und mit der Kriegszeit zusammengehangen, zum anderen an der größeren Zahl der Rekruten gelegen haben, die eine andere Religion hatten, aber vielleicht auch daran, dass man sich als Vielvölkerstaat verstand, der die religiösen Bedürfnisse der verschiedensten Untertanen zu befriedigen hatte. Es scheint, dass der Staat in dem Moment, da man von den Bürgern forderte, die staatsbürgerlichen Pflichten zu erfüllen und Militärdienst zu leisten, pro-aktiv von sich aus die Initiative ergriff, um einen finanziellen und organisatorischen Rahmen zu schaffen, um den Rekruten ihr Recht auf Religionsausübung zu gewährleisten und eine religiöse Betreuung aufzubauen. 
In diesem Sinne wurden noch vor Einführung der Militärpflicht in BosnienHerzegowina ausführliche Erkundigungen an verschiedenen Stellen eingeholt, um Konzepte zu entwickeln, wie man auf die religiösen Bedürfnisse der muslimischen Soldaten eingehen sollte:

„Was die Aufnahme von Muslimen in die k. u. k. Armee betraf, hatte sich das Kriegsministerium - noch bevor 1881 mit der Musterung bosnisch-herzegowinischer Wehrpflichtiger begonnen worden war - umfassend vorbereitet und Informationen über den Umgang mit muslimischen Soldaten in anderen europäischen Armeen eingeholt. An die österreichisch-ungarischen Militärattachés in Sofia, London, Montenegro, Paris, St. Petersburg und Bukarest war ein Fragebogen ergangen, in dem man nach den Aufnahmeregeln, den religiösen Festen, Gebetsräumen und nach muslimischer Militärgeistlichkeit gefragt wurde. Das provisorische Wehrgesetz für Bosnien und Herzegowina sah eine Reihe von Bestimmungen vor, die auf die muslimischen Wehrpflichtigen abgestimmt waren.“ ${ }^{\text {92 }}$

Im Unterschied dazu erfolgte der Aufbau der Militärseelsorge an religiösen Minderheiten im österreichischen Bundesheer der zweiten Republik eher auf Drängen von Rekruten und auf Initiative der Religionsgemeinschaften. Das Bundesheer re-agierte mehr auf die sich langsam verändernden gesellschaftlichen Realitäten der religiösen Diversifizierung im Bundesheer widerspiegelt, als dass es pro-aktiv handelte und ein Gesamtkonzept für die Behandlung von religiösen Minderheiten entwarf.

Dies kann man daran ablesen, dass es keine besonderen Erlässe und Regelungen für religiöse Minderheiten entsprechend der demographischen Entwicklung gab, sondern dass jeweils aus konkretem Anlass von Kritik oder Konflikten Regelungen erlassen wurden, die sich erst allmählich zu einem Gesamtkonzept zusammenfügten. So ist schon sehr auffällig, dass es für die Sikhs, die eine verschwindend kleine Minderheit darstellen (und wahrscheinlich auch in Zukunft darstellen werden) die ersten Regelungen gab, während es für orthodoxe Rekruten bis heute keine gibt. Zum anderen ist auffällig, dass für Muslime, die mittlerweile eine größere Minderheit darstellen als die Evangelischen bis heute keine flächendeckende Militärseelsorge etabliert ist. Selbst wenn es nun bald zu einem Vertrag mit zwei Imamen kommen sollte, so ist doch nicht erkennbar, dass hinsichtlich der finanziellen und personellen Rahmenbedingungen eine annähernde Gleichstellung zur evangelischen oder katholischen Militärseelsorge erreicht wird. Ähnliches gilt für die orthodoxe Militärseelsorge, die mit sehr bescheidenen Mitteln ihren Auftrag 2011 begonnen hat und wahrscheinlich auch noch weiterhin ausführen wird.

Prinzipiell drängt sich beim historischen Vergleich die Frage auf, ob die Ausgestaltung der Militärseelsorge nicht eher der demographischen Entwicklung und

92 Neumayer / Schmidl 2008, S. 99. 
dem Prinzip der Gleichbehandlung aller Bürger folgen sollte, d.h. dass die personelle und finanzielle Ausstattung der verschiedenen Militärseelsorgezweige entsprechend der Anzahl von Rekruten entwickelt und ein längerfristiges Gesamtkonzept des Umgangs mit religiösen Minderheiten entworfen werden sollte, in dem genaue Kriterien aufgestellt werden, ab welcher Anzahl von Rekruten man welche Form von religiöser Betreuung gewährleistet, inwieweit Büros und Räume für Gottesdienste zur Verfügung gestellt werden, wie Verpflegung, Dienstzeiten und Kleidung geregelt werden etc. Evangelische, Orthodoxe, Muslime, Sikhs, Adventisten, Altkatholische und noch weitere religiöse Minderheiten wie z.B. Jehovas Zeugen, Pfingstchristen, Baptisten, Orientalisch-Orthodoxe, Hindus, Buddhisten, Bahai, Aleviten u.a. sind österreichische Staatsbürger, die Wehrpflicht zu leisten haben. Sie sind teilweise bereits anerkannte Religionsgemeinschaften, teilweise haben sie den Status von eingetragenen Bekenntnisgemeinschaften. Manche sind nur als Vereine organisiert. Ungeachtet ihres religionsrechtlichen Status hat der Staat jedoch allen Staatsbürgern freie Religionsausübung zu gewähren, denn $\S 43$ Abs. 4 des Wehrgesetzes formuliert sehr allgemein und ohne jegliche Einschränkung auf den Status einer religiösen Minderheit: „Eine religiöse Betätigung darf jedoch nicht geschmälert werden.“ Insoweit wäre die Frage, inwieweit der Staat pro-aktiv tätig werden sollte, um zu erfassen, wie viele Soldaten des Heeres welche religiöse Prägung mitbringen, und von sich aus erwägen sollte, ob und welcher Bedarf evtl. besteht, um religiöse Bedürfnisse zu erfüllen und inwieweit Bedarf besteht, eine Militärseelsorge für die Betroffenen aufzubauen. Auch eine soziale und psychologische Betreuung von nicht-religiösen Soldaten ist, obwohl sie mittlerweile eine große Gruppe darstellen, nicht im Blick. Es geht dabei vornehmlich um ein professionelles Diversitätsmanagement einer staatlichen Organisation und die Verpflichtung der staatlichen Institution, dem staatlichen Auftrag zur Gewährung von Religions- und Weltanschauungsfreiheit nach Kriterien des Qualitätsmanagements und unter Wahrung der Äquidistanz zu den verschiedenen Religionsgemeinschaften Rechnung zu tragen. Zudem könnte sich das Heer dadurch als attraktiver Arbeitgeber positionieren. Die Armee steht hierbei vor Aufgaben, die sich für andere staatliche Institutionen wie Krankenhäuser, Pflegeeinrichtungen, Kindergärten oder Institutionen des Strafvollzugs ganz ähnlich stellen. ${ }^{93}$

\subsection{Die Kategorisierung von Frömmigkeit bzw. Glaubenspraxis}

Die dreistufige Kategorisierung der Frömmigkeit und nochmalige Unterscheidung von Bundesbediensteten und Präsenzdienern in den Regelungen für den Umgang mit religiösen Minderheiten im österreichischen Heer ist komplex und verwirrend. Darüber hinaus bringt sie in manchen Bereichen eine Ungleichbe-

93 Vgl. Reiss 2015, S. 156. 
handlung der verschiedenen Religionsgemeinschaften mit sich, die rechtlich problematisch und religionswissenschaftlich zudem unhaltbar ist. Dies betrifft vor allem die Kategorisierung der Frömmigkeit bzw. Glaubenspraxis.

Die Beobachtung, dass es in allen Religionen Personen gibt, die sich streng an die religiösen Traditionen und Pflichten halten, und dass es auf der anderen Seite Gläubige gibt (meistens die Mehrheit), die sich nicht streng an die religiösen Vorschriften halten und ihre Religion nur eingeschränkt praktizieren, ist zwar richtig, aber es sollte nicht dazu führen, dass der Staat oder die Religionsgemeinschaften Gläubige nach verschiedenen Graden klassifizieren und ihnen daraus ableitend gewisse religiöse Grundrechte gewähren oder vorenthalten.

Die gesamte Zeitordnung des Bundesheeres beruht darauf, dass man von praktizierenden (katholischen) Christen ausgeht, die traditionell die Mehrheit der österreichischen Bevölkerung darstellen. Der Sonntag ist dienstfrei, weil Christen die Möglichkeit gegeben werden soll, an diesem Sonntag die Kirche zu besuchen und ihn als Ruhetag zu begehen. Das Faktum, dass wahrscheinlich nur ca. $10 \%$ der christlichen Rekruten das tatsächlich tun, ändert nichts an dem rechtlichen Anspruch auf den Sonntag als dienstfreie Zeit. Gleiches gilt auch für den Besuch von Gottesdiensten an kirchlichen Festtagen. Niemand muss sich dafür rechtfertigen, ob man tatsächlich an Fronleichnam, Himmelfahrt, Ostermontag oder Mariä Himmelfahrt in den Gottesdienst gegangen ist. Auch bei evangelischen, altkatholischen oder methodistischen Rekruten ist nicht immer gesagt, dass sie am Karfreitag oder Reformationstag tatsächlich in die Gottesdienste gehen, für deren Besuch sie eine Dienstfreistellung erhalten können. Niemand käme auf die Idee von einem christlichen Rekruten zu verlangen, dass er eine Verpflichtungserklärung unterschreibt, in der er erklärt, dass er gewissenhaft seine Sonntagspflicht erfüllt oder regelmäßig während seines Präsenzdienstes alle Gottesdienste an Marienfeiertagen besucht. Genauso wenig ist von einem Muslim zu verlangen, dass er eine Verpflichtungserklärung unterschreibt, dass er die täglichen Gebete durchführt, am Freitagsgebet teilnimmt, im Monat Ramadan fastet, kein Schweinefleisch isst und keinen Alkohol trinkt, um in den Status eines „strenggläubigen Muslims“ zu kommen, der ihm die Möglichkeit bietet, diese Rechte wahrzunehmen. Es handelt sich dabei um die ganz normalen Vorschriften, die einen Muslim zu einem praktizierenden Muslim machen. Es ist kein Ausdruck einer Strenggläubigkeit oder besonderen Strenggläubigkeit, sondern eigentlich das Selbstverständliche, was man von einem jedem Muslim erwarten sollte, genauso wie man von einem praktizierenden Christen erwarten sollte, dass er Gottesdienste und christliche Feste besucht. Krainz schreibt zu recht: „Solche Einteilungen bergen jedoch die Gefahr, dass Vorannahmen und Vorurteile gefestigt werden und so Diskriminierungen der Betroffenen begünstigen. ${ }^{\text {“94 }}$ Auch der neu eingeführte Militärimam Abdulmedjid Sijamhodzic distanzierte sich in

94 Krainz 2012, S. 211. 
einem Interview umgehend von dieser Klassifizierung. ${ }^{95}$ Die Kategorisierung schafft Fremdzuschreibungen, die zu falschen Erwartungshaltungen führen und in unzulässiger Weise das Recht auf Religionsausübung zu einer Pflicht werden lassen. ${ }^{96}$ Die damit verbundenen Annahmen sind falsch, dass nur die Strenggläubigen sich für die Einhaltung des Ramadan oder für das Freitagsgebet oder Schweinefleisch freies Essen interessieren, wie umgekehrt nicht alle, die aus religiösen Gründen kein Schweinefleisch essen, auch jeden Tag beten und keinen Alkohol trinken. Es gibt sehr unterschiedliche Gründe, warum jemand in welchem Umfang seine Religion praktiziert oder es auch unterlässt. ${ }^{97}$ Dies kann sich auch (insbesondere durch Krisen) sehr schnell verändern. Das Heer kann jedem Angehörigen einer Religion nur die Möglichkeit geben, die religiösen Gebote einzuhalten. D.h. der Staat sollte jeden Muslim und jeden Christen als einen praktizierenden Gläubigen betrachten, selbst wenn er in der Realität vielleicht nur gelegentlich Gottesdienste besucht oder nur gelegentlich die Ritualgebete durchführt bzw. viele Vorschriften nicht einhält. Gleiches gilt für Juden, für Sikhs oder jede andere Religionsgemeinschaft. Viele liberale Juden halten sich nicht streng an das Sabbatgebot oder die Kaschrut-Regeln und viele „säkulare“ Juden beachten nicht die täglichen Gebete und gehen nur selten zum Synagogengottesdienst. Zugleich begehen aber die meisten Juden welcher Richtung auch immer das Passahfest als Familienfest und fasten am Jom Kippur. Auch hier hat der Staat m. E. nur die Möglichkeiten zu schaffen, dass jemand der will, die traditionellen Gebote und Vorschriften einhalten und die Feste begehen kann. Keineswegs ist darüber zu urteilen oder zu kontrollieren, ob und in welchem Maße jemand seine Religion tatsächlich praktiziert.

\subsection{Dienstfreistellung für Gebete und Feiertage}

Aufgrund der vorangegangen Überlegungen sollte bei religiösen Armeeangehörigen prinzipiell von praktizierenden Gläubigen ausgegangen werden. Allen Gläubigen, ungeachtet dessen ob sie sich selbst als gläubig oder strenggläubig betrachten oder von anderen eingestuft werden, sollte obligatorisch die Möglichkeit zur Freistellung für Gebetszeiten und Tage des Gottesdienstes gegeben werden, unabhängig davon, ob davon tatsächlich Gebrauch gemacht wird. D.h. katholische, evangelische, altkatholische, methodistische, orthodoxe u. a. Christen sollten am Sonntag frei haben, Muslime alternativ am Freitag, Juden und Adventisten alternativ am Samstag. Gegenwärtig ist dies nur für diejenigen, die als streng gläubig eingestuft werden und Präsenzdiener sind. Es ist m. E. allerdings

95 Vgl. http://www.dasbiber.at/content/nur-gott-weiss-wer-wirklich-glaeubig-ist, letzter Aufruf 20.10.2015.

96 Vgl. Krainz 2012, S. 209.

97 Vgl. Krainz 2012, S. 179-188, 201. 
nicht einzusehen, warum dies für Berufssoldaten und Bundesbedienstete bzw. bloße „Angehörige“ nicht gelten sollte. Da die Normdienstzeit vorgibt, dass sonntags dienstfrei ist, sollte die Zeit ggf. eingearbeitet werden. Aber so wie jedem Christen es offen steht, auch an Sonntagen oder an christlichen Feiertagen Dienst zu tun, sollte es natürlich auch Angehörigen anderer Religionen offenstehen - aus welchen Gründen auch immer - dieses Recht nicht in Anspruch zu nehmen, sich über die freien Zeiten hinwegzusetzen, die ihnen als Mitglied einer religiösen Gemeinschaft garantiert sind.

Allen Gläubigen, ungeachtet ihrer Glaubenspraxis und ihres Status im Bundesheer (d.h. Bundesbedienstete und Präsenzdiener) sollte desweiteren obligatorisch die Möglichkeit gegeben werden, an den großen Festen ihrer Religion vom Dienst freigestellt zu werden. Die bisherigen Regeln sind hier nicht schlecht, allerdings ist die Frage, warum evangelische Christen ihre besonderen freien Tage nicht einarbeiten müssen, während alle anderen dies tun müssen. Auch ist nicht einzusehen, warum jüdische Präsenzdiener mehr Rechte auf Feiertage haben als Beamte und Vertragsbedienstete. Zum anderen wäre es wichtig auch den orthodoxen Festkalender noch mit in die Erlässe mit einzubeziehen. D.h., dass ein orthodoxer Serbe z.B. für das orthodoxe Weihnachtsfest (7. Januar), für Karfreitag und das orthodoxe Osterfest oder für den St. Veitstag (Vidovdan, 28.6.) obligatorisch dienstfrei gestellt werden sollte (mit Einarbeitung). Durch das neue Islamgesetz wird es voraussichtlich notwendig werden, die Dienstfreistellungen für Muslime zu überarbeiten, denn in $\$ 13$ und $\$ 20$ werden nunmehr auch die schiitischen und alevitischen Feste erstmals inkludiert und explizit festgehalten, dass sie ebenso staatlich geschützt sind.

Außerdem wäre zu überlegen, ob nicht auch die Feste andrer religiöser Minderheiten (sofern sie im österreichischen Bundesheer Dienst tun) bei der Überarbeitung des Erlasses für die Minderheiten mit einbezogen werden. Selbst wenn dies im Moment kaum eingefordert wird, wäre es ein gutes Zeichen, um zu signalisieren, dass auf die religiösen Bedürfnisse aller Religionsgemeinschaften eingegangen wird. Warum sollten ein Hindu, ein Buddhist, ein Mormone weniger Recht darauf haben, seine Feiertage zu begehen? Jeder Angehörige einer Religion sollte den Anspruch darauf haben, zentrale Feiertage seiner Religion feiern zu können, ohne von den individuellen Entscheidungen seines Vorgesetzten abhängig zu sein. Dies sollte für Bundesbedienstete und Präsenzdiener gleichermaßen gelten, weil für alle gleichermaßen das Recht darauf besteht, dass die „religiöse Betätigung nicht geschmälert werden darf.“

\subsection{Verpflegung}

Die Einhaltung der religiösen Speisevorschriften ist im österreichischen Bundesheer weitgehend Standard. Es gibt aber immer noch Vorbehalte von manchen Muslimen, weil nicht garantiert werden kann, dass das Fleisch halal geschlachtet, 
d. h. geschächtet wurde. Im $\$ 12$ des neuen Islamgesetzes wird eingeräumt, dass bei „der Verpflegung von Mitgliedern der Religionsgesellschaften beim Bundesheer [...] auf die innerreligionsgesellschaftlichen Speisegebote Rücksicht zu nehmen“ ist. ${ }^{98}$ In den Erläuterungen zum Islamgesetz wird jedoch explizit festgehalten, dass aus $§ 12$ keine Verpflichtung abgleitet werden könne, dass die angebotene oder bereitgestellte Verpflegung den religiösen Speisegeboten entsprechen muss. Es sei ausreichend, wenn z. B. Speisen selbst mit- oder beigebracht werden können. Solche Formulierungen wären jedoch, soweit sie auf das das Bundesheer bezogen sind, ein enormer Rückschritt, da dies eigentlich bereits besser geregelt ist. ${ }^{99}$ Hinsichtlich der Einhaltung der jüdischen Speisegebote ist die Gewährleistung sehr viel schwieriger zu realisieren. Zum einen, weil dies nur eine sehr kleine Zahl von Rekruten betrifft, so dass der Aufwand der Bereitstellung einer koscheren Kost kaum lohnt, zum anderen, weil die Kaschrut-Reglementierungen sehr viel komplizierter sind als die Halal-Regeln. Es wäre allerdings zu überlegen, ob nicht die generelle Bereitstellung einer koscheren Kost für Juden und Muslime eine praktikable Lösung wäre, da die jüdischen Speisevorschriften auch die muslimischen abdecken. Im Blick auf Sikhs, Hindus und Buddhisten, aber auch viele Gläubige anderer Religionen und Menschen, die vermehrt aus weltanschaulichen Gründen den Verzehr von Tieren (und tierischen Produkten) ablehnen, ist zu überlegen, ob nicht grundsätzlich eine vegetarische, besser noch vegane Kost parallel zur Normalkost und zur koscheren bzw. Halal-Kost angeboten werden könnte. Darauf könnten z.B. auch orthodoxe oder orientalisch-orthodoxe Christen an ihren Fastentagen bzw. zu ihren Fastenzeiten zurückgreifen, denn bei beiden Gruppen handelt es sich beim Fasten größtenteils um einen völligen Verzicht auf Fleisch und tierische Produkte. Wenn eine solche Kost als dritte Auswahlmöglichkeit angeboten würde, so könnten wohl weitgehend alle Speisevorschriften religiöser Gruppierungen eingehalten werden.

\subsection{Bekleidung}

Die Bekleidungsregelungen des österreichischen Bundesheers im Blick auf die Kippa für Juden sowie die Regelungen für die Sikhs, die sich an das religiöse Gebot halten wollen, nicht Haare und Bart zu schneiden, sind vorbildlich. Was

98 Islamgesetz $§ 12$ Abs 2.

99 Erläuterung zu §12 des Islamgesetzes: „Der Begriff, Rücksicht zu nehmen“ ist dabei so zu verstehen, dass nach Maßgabe der Möglichkeiten in der Vollziehung Alternativen zu Speisen, die aufgrund religiöser Bestimmungen nicht konsumiert werden dürfen, zu ermöglich sind. Daraus kann keine Verpflichtung abgeleitet werden, dass die angebotene oder bereitgestellte Verpflegung den religiösen Speisegeboten entsprechen muss. Als Alternative wäre z.B. ausreichend, dass Speisen selbst mit- oder beigebracht werden können.“ 
fehlt, ist eine Regelung für das Tragen des Kopftuches für muslimische Soldatinnen. ${ }^{100}$ Die Regelung, dass „besonders strenggläubige Muslime“ einen Bart tragen dürfen, ist jedoch äußerst fragwürdig. Zum einen, weil es keine religiöse Vorschrift im Islam gibt, einen Bart zu tragen. Dies ist eher ein persönlicher Ausdruck dafür, dass man sich einer bestimmten Gruppe, z. B. der Muslimbruderschaft oder der salafistischen Bewegung, zugehörig fühlt bzw. einer Tradition (Sunna) oder Modeerscheinung folgt. Zum anderen, weil die „,besonders strenggläubigen Muslime“ ihren Glauben auch nicht anders leben als „normal“ praktizierende Muslime. Der einzige Unterschied ist vielleicht der, dass sie dies mit fundamentalistischem und individuell-rigoristischem Gedankengut und mit politisch-gesellschaftlichen Forderungen verbinden, die die Scharia den menschlichen Gesetzen überordnen und sich bewusst von den „Ungläubigen“ durch äußerliche Kennzeichen abgrenzen wollen. ${ }^{101}$ Ist es allerdings nicht höchst fragwürdig, islamistischen Gruppierungen einen besonderen Status innerhalb der Armee zu geben und sie als besonders strenge Vertreter des Islam zu bezeichnen $?^{102}$ Ahmad Muhammad al-Tayyeb, der Großscheich der bedeutendsten sunnitischen Hochschule al-Azhar und somit höchste sunnitische Autorität, trägt jedenfalls keinen Bart. Heißt das, dass er nach der Einstufung des österreichischen Bundesheers nicht als „besonders Strenggläubiger“ gelten würde? Schließlich stellt sich die Frage, warum man gerade im österreichischen Bundesheer eine solche Erlaubnis gibt, angesichts dessen, dass es in den meisten islamisch geprägten Ländern nicht erlaubt ist, in der Armee einen Bart zu tragen.

100 Eine erste muslimische Soldatin gibt es bereits. 2012 strahlte das ORF eine Sendung aus, in der Melek Yapakci interviewt wurde über ihren Dienst: „Gott und Vaterland Muslime im Bundesheer“. In: ORF2: „kreuz und quer“, 23.10.2012 (http://zukunft.orf. at/index.php?sid=82\&pvi_id=1331, letzter Aufruf 7.5.2015). Sie trägt zwar kein Kopftuch, aber es wäre erstaunlich, wenn es nicht bald auch erste Rekrutinnen gibt, die das Kopftuch tragen möchten.

101 Salafisten, die den Bart als Pflicht betrachten, berufen sich interessanterweise auf mündliche Überlieferungen, die die Barttragepflicht vornehmlich damit begründen, dass sich die Muslime dadurch äußerlich von den „Ungläubigen“, womit insbesondere Juden und Christen gemeint sind, unterscheiden müssen. Vgl. http:/www.fataawa.de/Fatawaas/ 7.Verhalten $\% 20 \& \% 20$ Moral $/ 2$.schlechtes $\% 20$ Verhalten/0083.pdf, letzter Aufruf 9.5.2015.

102 Vgl. http://www.genios.de/presse-archiv/artikel/FURC/20090917/besondere-baertemuslime-im-oesterr/0700850820670720690952009\%2009171736000047.html, letzter Aufruf 3.5.2015. 


\section{Konklusion}

Das österreichische Bundesheer ist ähnlich wie eine Anstalt des Strafvollzugs, ein staatliches Krankenhaus oder ein Pflegeheim eine Institution, in der Menschen eine beträchtliche Zeit verbringen müssen, in der es gewisse Einschränkungen im Blick auf die Kontaktaufnahme nach Außen gibt - entweder weil die Bewohner nur eingeschränkt oder gar nicht dazu fähig sind, selbständig Kontakt aufzunehmen (Krankenhaus, Pflegeheim) oder weil es Einschränkungen von Seiten der Institution hinsichtlich der Kontaktaufnahme von Außen gibt (Strafvollzug, Armee) ${ }^{103}$ Für den Staat, jeweils vertreten durch das Institutionsmanagement, ergibt sich in all diesen Institutionen eine besondere Verantwortung auf religiöse und kulturelle Diversität einzugehen, denn die Betroffenen sind in den Institutionen in ihrer individuellen Lebensführung eingeschränkt. Ein Mikrokosmos der Gesellschaft ist vorhanden, was sich z. B. auch dadurch zeigt, dass es oftmals eigene Infrastrukturen gibt mit einer Kantine, Laden und Wäschereien, mit eigenen Vorschriften und Regeln der Essenszeiten und der Hygiene, der Bekleidung und der Freizeitgestaltung, die das private Leben massiv betreffen und es einschränken, mit eigenen sozialen, psychologischen und medizinischen Diensten. Zudem sind die genannten Institutionen auch Orte, an denen es oftmals zu Krisen kommt, ohne dass die nächsten Verwandten und Freunde dies sofort durch eine dauernde Präsenz und Gespräche auffangen könnten: Krankheiten, Krisen, Konflikte mit anderen Insassen oder mit Bediensteten der Einrichtung, einschneidende Ereignisse im Familienleben, die Begegnung mit dem Tod müssen innerhalb der Institution verarbeitet werden. Die religiöse und kulturelle Diversifizierung der Gesellschaft zeigt sich in solchen Mikrokosmen schneller als in der Gesamtgesellschaft. Insoweit sind diese Institutionen Versuchslabore der Inklusion von Minderheiten, die längerfristig möglicherweise auch Muster und Vorbilder für die gesamte Gesellschaft sein können.

In vielen staatlichen Institutionen wurden in den letzten Jahren praktische Regelungen getroffen, um die religiösen Rechte der Minderheiten zu wahren, es fehlt jedoch an Gesamtkonzepten für die Institutionen. Selten werden die Fragestellungen über den eigenen Bereich hinaus miteinander verbunden. ${ }^{104}$ Dabei sind die Fragen und Probleme im Blick auf die religiöse Betreuung oft ähnlich: Es geht an erster Stelle um die Einhaltung von religiösen Speiseregeln, es geht um die Bereitstellung von Zeiten und Orten für das Gebet bzw. die Gottesdienste, es geht um die Regelung für die Fastenzeiten, es geht um die Regelung einer religiösen Betreuung. Was die Speiseregeln angeht, so könnten auch transinstitutionelle Regelungen getroffen werden. Wenn z. B. koscheres Essen bzw. Halal-Kost nicht nur für das Bundesheer, sondern auch gleichzeitig für das Krankenhaus, das Al-

103 Teilweise wird für solche Institutionen der Begriff „,totale Institutionen“ benutzt. Vgl. Goffman 1973.

104 Reiss 2015. 
tenheim, die Kindergärten, Schulen und die Anstalten des Strafvollzugs in einer bestimmten Region organisiert würde, könnte manches sehr viel rationeller und einfacher geregelt werden. Auch wäre es wahrscheinlich hilfreich miteinander abzusprechen, welche Regelungen sich bereits bewährt haben und wo es zu Konflikten gekommen ist, um das institutionelle Wissen von Praktikern mit anderen auszutauschen, die vor ähnlichen Problemen stehen. Möglicherweise könnten regionale oder nationale anwendungsorientiert forschende religionswissenschaftliche Kompetenzzentren solche inter- bzw. multi-institutionelle Dialoge initiieren oder begleiten, denn religionswissenschaftliche Kompetenz ist mit Sicherheit hilfreich in solchen Prozessen. Es geht darum anwendungsorientiertes wissenschaftliches Wissen und praktisches Wissen in Institutionen miteinander zu verbinden und gesellschaftliche Fragestellungen mit Mitteln transdisziplinärer Forschung zu bearbeiten, um praktische Lösungen für konkrete vorhandene oder potentielle Konfliktfelder zu analysieren, zu evaluieren und eventuell auch zu verbessern. Parallelen sehe ich auch in dem Fehlen von Regelungen, die das Element der demographischen Entwicklung berücksichtigt. ${ }^{105}$ Bei den bisherigen Regelungen wird in den staatlichen Institutionen kaum die Zahl der betroffenen Patienten, Klienten, Insassen bzw. Soldaten berücksichtigt. Dies fällt insbesondere bei der Betrachtung der Orthodoxen auf, die erst in jüngster Zeit ins Blickfeld geraten, obwohl sie schon seit längerem eine größere Gruppe in allen Institutionen darstellen.

\section{Literaturangaben}

\section{Quellen}

Bundesministerium für Landesverteidigung (Hg.): Dienstbetrieb; Behandlung religiöser Minderheiten - Einberufung und Verwendung; Zusammenfassende Richtlinien Neufassung; GZ S93109/9-FGG1/2006 v. 30. Aug. 2006, in: Verlautbarungsblatt I, Nr. 53/2006.

Bundesministerium für Landesverteidigung und Sport (Hg.): Religiöse Betreuung für Angehörige des Bundesheeres, die Mitglieder der IGGiÖ sind; Richtlinien -Fassung 2015, Erlass vom 19. Juni 2015, GZ S90598/1-Präs/2015, in: Verlautbarungsblatt I. Nr. 35/2015.

Bundesministerium für Landesverteidigung und Sport (Hg.): Religiöse Betreuung für Angehörige des Bundesheeres, die Mitglieder der IGGiÖ sind; Richtlinien -Neufassung 2015, Erlass vom 15. Juli 2015, GZ S90598/5-Präs/2015: in: Verlautbarungsblatt I, Nr. 43/2015.

Erläuterungen zum Islamgesetz 2014, available at: http://www.parlament.gv.at/PAKT/ VHG/XXV/ME/ME_00069/fname_367085.pdf [8.5.2015]. 
Islamgesetz 2014. Bundesgesetz, mit dem das Gesetz betreffend die Anerkennung der Anhänger des Islam als Religionsgesellschaft geändert wird (Entwurf), available at: http://www.parlament.gv.at/PAKT/VHG/XXV/ME/ME_00069/fname_367084.pdf [8.5.2015].

Orientalisch-Orthodoxes Kirchengesetz 2003. Bundesgesetz über äußere Rechtsverhältnisse der orientalisch-orthodoxen Kirchen in Österreich (Orientalisch-orthodoxes Kirchengesetz; OrientKG), BGBl. 20/2003, 25.4.2003, 103-105, available at: https:// www.ris.bka.gv.at/Dokumente/BgblPdf/2003_20_1/2003_20_1.pdf [3.5.2015].

Orthodoxengesetz 1967. Bundesgesetz vom 23. Juni 1967 über äußere Rechtsverhältnisse der griechisch-orientalischen Kirche in Österreich, BGBl. 229/1967, 14.7.1967, 13501353, available at: https://www.ris.bka.gv.at/Dokumente/BgblPdf/1967_229_0/1967_ 229_0.pdf [3.5.2015].

Protestantengesetz 1961. Bundesgesetz vom 6. Juli 1961 über äußere Rechtsverhältnisse der Evangelischen Kirche. In: Bundesgesetzblatt für die Republik Österreich 1961, 19.7.1961, 957-961, available at: https://www.ris.bka.gv.at/Dokumente/BgblPdf/ 1961_182_0/1961_182_0.pdf [1.5.2015].

Statistik Austria (Hg.): Migration\& Integration. Zahlen, Daten, Indikatoren 2014, Wien 2014.

Statistik Austria (Hg.): Volkszählung 2001. Hauptergebnisse I - Österreich, Wien 2002. Wehrgesetz 1955. Bundesgesetz vom 7. September 1955, womit Bestimmungen über das Wehrwesen erlassen werden (Wehrgesetz). In: Bundesgesetzblatt für die Republik Österreich 1955, 21.9.1955, 905-918, available at: https://www.ris.bka.gv.at/Doku mente/BgblPdf/1955_181_0/1955_181_0.pdf [1.5.2015].

\section{Sekundärliteratur}

Berger, Michael: Eisernes Kreuz - Doppeladler - Davidstern / Juden in deutschen und österreichisch-ungarischen Armeen, Berlin 2010.

Goffman, Erving: Asyle. Über die soziale Situation psychiatrischer Patienten und anderer Insassen, Frankfurt am Main 1973.

Gröger, Roman-Hans / Ham, Claudia / Sammer, Alfred (Hg.): Militärseelsorge in Österreich. Zwischen Himmel und Erde. Mit einem Beitrag von Julius Hanak. Styria, Graz u.a. 2001.

Hanak, Julius: Militärseelsorge - Versöhnte Vielfalt. Die Bedeutung der ökumenischen Beziehungen für die Arbeit in der Militärseelsorge aus der Sicht einer Diasporakirche. In: Truppendienst 1992/6, S. 549-553.

Ham, Claudia: Von den Anfängen der Militärseelsorge bis zur Liquidierung des Apostolischen Feldvikariates im Jahre 1918, in: Gröger, Roman-Hans / Ham, Claudia / Sammer, Alfred (Hg.): Militärseelsorge in Österreich. Zwischen Himmel und Erde. Styria, Graz u. a. 2001, S. 13-98.

Heine, Susanne / Lohlker, Rüdiger / Potz, Richard: Muslime in Österreich. Geschichte, Lebenswelt, Religion, Innsbruck-Wien 2012.

Khouja, Mouddar: „Europäische Militärseelsorge zwischen Christentum, Islam und Säkularisierung aus der Sicht der Islamischen Glaubensgemeinschaft in Österrreich“. In: Militär \& Seelsorge 2008/23, Wien, S. 31-34. 
Krainz, Ulrich: Zur Problematik kultureller Integration: Junge muslimische Männer beim Österreichischen Bundesheer und Zivildienst, Marburg 2012.

Marik-Lebeck, Stephan: Die muslimische Bevölkerung Östereichs: Bestand und Veränderung 2001-2009, in: Janda, Alexander / Vogl, Mathias: Islam in Österreich, Wien 2010, S. 5-9.

Neumayer, Christoph / Schmidl, Erwin A. (Hg.): Des Kaisers Bosniaken. Die bosnischherzegowinischen Truppen der k.u. k. Armee. Geschichte und Uniformierung von 1878 bis 1918 , Wien 2008.

Reichl-Ham, Claudia: „Die Militärseelsorge in Geschichte und Gegenwart“. In: Militär \& Seelsorge 2005. Themenheft 4, Evangelische Militärsuperintendentur: Wien, S. 548.

Reiss, Wolfram: Auswirkungen der religiösen Pluralität auf staatliche Institutionen und die Anstaltsseelsorge, in: Polak, Regina / Reiss, Wolfram (Hg.): Religion im Wandel. Transformation religiöser Gemeinschaften in Europa durch Migration. Interdisziplinäre Perspektiven, Wien 2015, S. 147-186.

Schachinger, Werner: Die Bosniaken kommen! Elitetruppe in der K und K Armee, 1879_ 1918, Graz 1994.

Schmidl, Erwin A.: Habsburgs jüdische Soldaten 1788-1918, Böhlau : Wien 2014.

Schmidl, Erwin A.: Juden in der k. (und) k. Armee 1788-1918. Jews in the Habsbourg Forces, Österreichisches Jüdisches Museum in Eisenstadt, Eisenstadt 1989.

Sladek, Gerhard: „Der muslimische Gebetsraum in der Maria Theresien-Kaserne“. In: Militär \& Seelsorge 2011a. Themenheft 30/1, Gebetsstätten für Soldaten des Österreichischen Bundesheeres, Teil 1, Evangelische Militärsuperintendentur: Wien, S. 2426.

Sladek, Gerhard: „Die Evangelische Auferstehungskirche in Wien-Neubau“. In: Militär \& Seelsorge 2011b. Themenheft 30/1, Gebetsstätten für Soldaten des Österreichischen Bundesheeres, Teil 1, Evangelische Militärsuperintendentur: Wien, S. 18-21.

Trauner, Karl-Reinhart: „Dienstbetrieb; Behandlung religiöser Minderheiten ...“. Die rechtlichen Regelungen für den Umgang mit sog. Religiösen Minderheiten im Österreichischen Bundesheer [Vortrag am 13.5.2009 im Rahmen des Seminars „Muslime in der Armee“ von Prof. Dr. Wolfram Reiss, Typoskript 45 Seiten].[2009a].

Trauner, Karl-Reinhart: „Religionsausübung im Österreichischen Bundesheer“. In: Militär \& Seelsorge 2009. Themenheft 20, Evangelische Militärsuperintendentur: Wien, S. 17-28.[2009b].

Trauner, Karl-Reinhart: „Die ehemalige evangelische Garnisonskirche in Wien-Alsergrund“. In: Militär \& Seelsorge 2011b. Themenheft 30/1, Gebetsstätten für Soldaten des Österreichischen Bundesheeres, Teil 1, Evangelische Militärsuperintendentur: Wien. 